\title{
Brain imaging and human nutrition: which measures to use in intervention studies?
}

Stéphane V. Sizonenko ${ }^{1}$, Claudio Babiloni ${ }^{2,3}$, Eveline A. de Bruin ${ }^{4}$, Elizabeth B. Isaacs ${ }^{5}$, Lena S. Jönsson ${ }^{6}$, David O. Kennedy ${ }^{7}$, Marie E. Latulippe ${ }^{6}$, M. Hasan Mohajeri $^{8}$, Judith Moreines $^{9}$, Pietro Pietrini ${ }^{10}$, Kristine B. Walhovd ${ }^{11}$, Robert J. Winwood ${ }^{12}$ and John W. Sijben ${ }^{13}$

1. Division of Development and Growth, Department of Child and Adolescent Medicine, School of Medicine and University Hospital, Geneva, Switzerland

2. Department of Molecular Medicine, University of Rome 'La Sapienza', Rome, Italy

3. IRCCS San Raffaele Pisana, Rome, Italy

4. Unilever R\&D Vlaardingen, Vlaardingen, The Netherlands

5. Childhood Nutrition Research Centre, UCL Institute of Child Health, London, UK

6. ILSI Europe a.i.s.b.I., Avenue E. Mounier 83, Box 6, B-1200 Brussels, Belgium

7. Brain, Performance and Nutrition Research Centre, Northumbria University, Newcastle, UK

8. DSM Nutritional Products, R\&D Human Nutrition and Health, Basel, Switzerland

9. Pfizer Consumer Healthcare, 5 Giralda Farms, Madison, NJ, USA

10. Laboratory of Clinical Biochemistry and Molecular Biology, University of Pisa Medical School, Pisa, Italy

11. Psychology Department, Center for the Study of Human Cognition, University of Oslo, Oslo, Norway

12. DSM Nutritional Products (UK) Limited, Delves Road, Heanor, Derbyshire, UK

13. Nutricia Advanced Medical Nutrition, Danone Research Centre for Specialised Nutrition, Wageningen, The Netherlands 


\section{Table of Contents}

MRI: brain structural, metabolic and functional assessments for nutritional research

Electroencephalography and magnetoencephalography: measuring brain electrical and magnetic activities

S12-S15

Near-IR spectroscopy: measuring cerebral blood flow and haemodynamic responses

Positron emission tomography imaging: anatomical, metabolic and functional assessments for nutritional research

Single-photon emission computerised tomography imaging: anatomical, metabolic and functional assessments for nutritional research

Key words: Nutrition: MRI: Electroencephalography: Near-IR spectroscopy: Positron emission tomography

Corresponding author: ILSI Europe a.i.s.b.l. - Avenue E. Mounier 83, Box 6 - 1200 Brussels - Belgium fax: +32 276200 44, email: publications@ilsieurope.be

Abbreviations: AD, Alzheimer's disease; ADHD, attention-deficit hyperactivity disorder; BOLD, blood oxygen level dependent; CBF, cerebral blood flow; CNS, central nervous system; deoxy-Hb, deoxygenated $\mathrm{Hb}$; DTI, diffusion tensor imaging; EEG, electroencephalography; EP, evoked potential; ERP, event-related potential; FA, fractional anisotropy; FDG, $\left[{ }^{18} \mathrm{~F}\right]$ fluoro-2-deoxy-D-glucose; fMRI, functional MRI; ${ }^{1} \mathrm{H}-\mathrm{MRS}$, proton spectroscopy; ILSI, International Life Sciences Institute; IQ, intelligence quotient; IUGR, intrauterine growth retardation; LC-PUFA, long-chain PUFA; MEG, magnetoencephalography; MR, magnetic resonance; MRS, magnetic resonance spectroscopy; NAA, $N$-acetylaspartate; NIRS, near-IR spectroscopy; oxy-Hb, oxygenated $\mathrm{Hb} ;{ }^{31} \mathrm{P}-\mathrm{MRS}$, phosphorus spectroscopy; PET, positron emission tomography; rCBF, regional cerebral blood flow; SPECT, single-photon emission computerised tomography; VBM, voxel-based morphometry.

This paper was published as a supplement to British Journal of Nutrition, publication of which was supported by ILSI Europe. The paper has undergone the standard journal formal review process and may be cited.

(C) ILSI Europe [2013]. The online version of this paper is published within an Open Access environment subject to the conditions of the Creative Attribution-NonCommercial-ShareAlike licence $<$ http://creative commons.org/licenses/by-nc-sa/3.0/>. The written permission of Cambridge University Press must be obtained for commercial re-use. 
The present review describes brain imaging technologies that can be used to assess the effects of nutritional interventions in human subjects. Specifically, we summarise the biological relevance of their outcome measures, practical use and feasibility, and recommended use in short- and long-term nutritional studies. The brain imaging technologies described consist of MRI, including diffusion tensor imaging, magnetic resonance spectroscopy and functional MRI, as well as electroencephalography/magnetoencephalography, near-IR spectroscopy, positron emission tomography and single-photon emission computerised tomography. In nutritional interventions and across the lifespan, brain imaging can detect macro- and microstructural, functional, electrophysiological and metabolic changes linked to broader functional outcomes, such as cognition. Imaging markers can be considered as specific for one or several brain processes and as surrogate instrumental endpoints that may provide sensitive measures of short- and long-term effects. For the majority of imaging measures, little information is available regarding their correlation with functional endpoints in healthy subjects; therefore, imaging markers generally cannot replace clinical endpoints that reflect the overall capacity of the brain to behaviourally respond to specific situations and stimuli. The principal added value of brain imaging measures for human nutritional intervention studies is their ability to provide unique in vivo information on the working mechanism of an intervention in hypothesis-driven research. Selection of brain imaging techniques and target markers within a given technique should mainly depend on the hypothesis regarding the mechanism of action of the intervention, level (structural, metabolic or functional) and anticipated timescale of the intervention's effects, target population, availability and costs of the techniques.

The brain is the most complex organ in the human body. It contains approximately 100 billion neurons, with each being connected by synapses to several thousands of other neurons. The brain controls physiological functions including, but not limited to, the sleep/wake cycle, arousal/attention, perception, mood, motivation, emotion, appetite/satiety, reward, learning/memory, speech, planning/executive processes and voluntary movements. The brain is a metabolically highly active organ that utilises a relatively large proportion of total nutrient and energy intake throughout the lifespan. Furthermore, the development and repair of neural tissue depends on the proper intake of essential nutrients, minerals and vitamins. Therefore, what we eat, or refrain from eating, may have an important impact on our cognitive ability and mental performance. There are two key areas in which diet plays an important role: supporting motor and cognitive neurodevelopment in children and preventing neurodegeneration and cognitive decline during ageing.

Neuronal and behavioural responses to nutrients are complex and their relationships to each other are often unclear. Nevertheless, there are several well-described routes by which diet may affect neurochemistry and brain function. Food and nutrient intake can modulate the availability of precursors or act as enzyme cofactors required for the synthesis and function of neurotransmitters, neurotrophic factors and psychoactive hormones. Dietary precursors participate in the formation and composition of neural membranes and synapses. Nutrients also affect cerebral blood flow (CBF), with a direct influence on energy and nutrient availability in the brain ${ }^{(1)}$. Some of the nutritional effects on brain function (e.g. changes related to cell signalling and energy supply) may be short lasting. For example, acute tryptophan depletion in women vulnerable to depressive symptoms has been shown to provoke a short-term relapse of clinically significant depressive symptoms ${ }^{(2)}$. On the other hand, supplementation of nutrients might have long-term effects on brain structure and function. For example, nutrient enrichment in preterm infants can affect neurodevelopmental outcomes and brain structure years, and even decades, after a short-term intervention $^{(3)}$. During the last few decades, the body of evidence from both observational and intervention human studies investigating the modulation of brain function by nutrients has grown dramatically. We now have a solid basis for translation into hypothesis-driven intervention studies and, ultimately, into evidence-based practices.

The magnitude of the economic and societal burden related to brain dysfunction is becoming increasingly evident. A recent study by the European College of Neuropsychopharmacology has indicated that $38.2 \%$ of the European Union population, or 168 million people, suffer from a mental disorder ${ }^{(4)}$. This was estimated to cost $€ 798$ billion in $2010^{(5)}$. The potential of nutrition to reduce the burden of impaired brain function has been illustrated by many studies reporting links between either poor nutrient intake or nutrient enrichment and brain function across the lifespan, from (pre)term infants to the elderly, and in various neurodevelopmental, neurological and psychiatric conditions ${ }^{(1,6-10)}$.

Despite great progress in the fields of neuroscience, neuropsychology and nutritional science in terms of understanding the relationships between brain function and nutrition, research assessing these long-term relationships, as well as human data regarding mechanisms of action, is hindered by practical feasibility or methodological constraints. In 2009, the Nutrition and Mental Performance Task Force of the European Branch of the International Life Sciences Institute (ILSI Europe) convened a workshop to evaluate the methodological challenges and opportunities related to studying the long-term effects of nutrition ${ }^{(11)}$. One recommendation from the workshop was to include brain imaging biomarkers as secondary endpoints in future intervention studies to produce study outcomes that supplement clinical or cognitive measures. Brain imaging biomarkers might improve our understanding of mechanisms of action and may potentially provide more sensitive measures that predict long-term effects earlier, thereby shortening the required trial duration ${ }^{(12)}$.

The aim of the present review was to provide a comprehensive overview of brain imaging techniques and the existing knowledge regarding the quality of imaging markers commonly used to assess brain structure and functions in human subjects. Specifically, we describe MRI and its multimodal assessment capacity, electroencephalography (EEG)/ magnetoencephalography (MEG), near-IR spectroscopy (NIRS), 
positron emission tomography (PET) and single-photon emission computerised tomography (SPECT) from the perspective of how they could have a place in nutritional intervention studies (Table 1). We have included a description of the aforementioned brain imaging techniques, the biological relevance of their measures, their practical feasibility, their sensitivity to age and in specific populations, and their recommended use in nutritional intervention studies. Such descriptions are expected to contribute to the identification of an appropriate set of relevant imaging measures with two main features. On the one hand, these techniques may allow the measurement of neurostructural, neurophysiological and neurochemical changes occurring over the lifespan and after nutritional interventions. On the other hand, they may elucidate the specific biological processes implicated in the changes in brain function during development and ageing and the means by which a nutritional intervention can modulate these changes. Of particular note, we have focused on the general population, especially those age groups that may be particularly sensitive to factors influential in periods of rapid brain development or to deteriorating brain function (e.g. infants and elderly).

\section{MRI: brain structural, metabolic and functional assessments for nutritional research}

\section{MRI techniques as a multimodal approach}

The advent of non-invasive MRI was a breakthrough to assess the human brain in vivo, greatly expanding the possibilities of investigating brain structure and function. It was originally developed as a medical imaging tool to provide detailed scans of the structures of internal organs, using magnetic fields and radiofrequency pulses. The MRI scanner uses a very powerful magnetic field to align atoms in the body. Radiofrequency pulses are then applied to disturb this alignment; as the nuclei return to alignment, they rotate and produce an electrical field that the scanner detects and uses to produce images. In the case of the brain, MRI scans provide detailed pictures of grey and white matter, vessels, cerebrospinal fluid and bone. Clinically, neuroradiologists usually interpret scans by visual inspection; however, in order to reveal more subtle features, other techniques that depend on postacquisition processing of the scans have been developed. The combination of MRI as a multimodal tool with postacquisition processing techniques provides a powerful technology for the study of the effects of nutrition on brain development and ageing. Within the broad divisions of macro- and microstructural, metabolic and functional imaging, a variety of techniques have emerged from magnetic resonance (MR), leading to a multimodal assessment of the brain.

For the examination of overall brain structure, a threedimensional anatomical dataset of $\mathrm{T} 1$ - and T2-weighted images, basic scans that provide a good contrast between grey matter and white matter, is collected, allowing reconstruction of the brain in three planes. Diffusion-weighted imaging and diffusion tensor imaging (DTI) datasets provide measures of water diffusion properties within the tissue and determine the microstructural characteristics of white and grey matter. In addition, magnetic resonance spectroscopy (MRS) based on proton $\left({ }^{1} \mathrm{H}-\mathrm{MRS}\right)$ and ${ }^{31} \mathrm{P}\left({ }^{31} \mathrm{P}-\mathrm{MRS}\right)$ magnetic properties measures the levels of different metabolites in body tissues, and functional MRI (fMRI) can be used to reveal brain structures and processes associated with perception, thought and action in response to sensory stimuli. The neural activity of the brain is closely linked to changes in blood flow and blood oxygenation in the brain (known as haemodynamics). Additional details on these measurements are given in Table 1.

Costs of MRI may vary regionally but are relatively high, not only due to the scanning time (depending on the number of MR sequences needed) and the cost of the equipment, but also in terms of image post-processing and analysis.

\section{$M R I$ acquisition, post-processing and MRI-derived measures}

In human subjects, MRI scans are most commonly obtained using a scanner with a magnetic field strength of 1.5 or $3 \mathrm{~T}$. All studies begin with the acquisition of scans using an imaging protocol designed to provide the information best suited to the chosen method of analysis. In order to compare different groups of a clinical/research study, the image signal and its properties need further post-processing operations to gather useful, reliable and comparable data. Different types of data are provided by the different methods. Some of the most widely used protocols and their respective post-processing considerations are described in the following sections.

Structural MRI. Morphometry and volumetrics refer to the measurement of physical form characteristics such as volumes of brain structures or thickness of cortices. Originally, these could only be measured manually by drawing about the perimeter of a structure on a series of $\mathrm{T} 1-\mathrm{T} 2$ conventional scans and then calculating the volume. Because it was time consuming and prone to error in some instances, its use was also restricted to structures that were clearly delineated (e.g. the hippocampus) rather than to those with less clear boundaries (e.g. some frontal lobe areas). Semi-automated and fully automated methods that label the neuroanatomical structures on the basis of probability information obtained from a training set of images that have been manually labelled have now become available ${ }^{(13)}$. The volumes of these structures (Fig. 2) are calculated and can then be used in statistical analyses. Cortical thickness can be estimated by means of an automated surface reconstruction scheme ${ }^{(14-20)}$, and scans from different time points or individuals can be compared at each vertex across the entire cortical mantle and may be related to other variables of interest. These techniques have been validated via histological $^{(21)}$ and manual measurements ${ }^{(22)}$. The cortical surface can also be parcellated into a number of different regions of interest, for which information on surface area, thickness and volume can be estimated ${ }^{(23)}$.

Voxel-based morphometry (VBM) ${ }^{(24)}$ was designed to investigate local differences in the distribution of grey and white matter in the brain. The scans are segmented into separate grey and white matter images and entered into the VBM analysis; for analytical purposes, the brain is divided into small 


\section{N British Journal of Nutrition}

Table 1. Summary of the key features of imaging measurements

\begin{tabular}{|c|c|c|c|c|c|c|c|c|c|}
\hline Method & Measures & $\begin{array}{l}\text { Structure, function } \\
\text { and metabolism }\end{array}$ & $\begin{array}{l}\text { Biological and } \\
\text { clinical relevance }\end{array}$ & Acute/chronic & Temporal/spatial & Age & Availability & Cost & Remarks \\
\hline \multicolumn{10}{|l|}{ MRI, fMRI and MRS } \\
\hline Structural 3D MRI & $\begin{array}{l}\text { Grey/white matter density } \\
\text { and volumes and } \\
\text { cortical thickness and } \\
\text { folding; proton charac- } \\
\text { teristics, e.g. density } \\
\text { and relaxation times }\end{array}$ & $\begin{array}{l}\text { Gross neural } \\
\text { macrostructure }\end{array}$ & $\begin{array}{l}\text { Overall brain growth } \\
\text { or atrophy; brain } \\
\text { maturation }\end{array}$ & $\begin{array}{l}\text { Acute/chronic. } \\
\text { Excellent for } \\
\text { studying the long- } \\
\text { term effects of } \\
\text { early intervention }\end{array}$ & $\begin{array}{l}\text { Good spatial } \\
\text { resolution }\end{array}$ & $\begin{array}{l}0-6 \text { months; } \\
\geq 4 \text { years* }\end{array}$ & High & Medium & $\begin{array}{l}\text { Non-invasive; becoming } \\
\text { more available as } \\
\text { scanners proliferate; } \\
\text { variety of analysis } \\
\text { tools available; high } \\
\text { reliability }\end{array}$ \\
\hline DTI & $\begin{array}{l}\text { Diffusion measures } \\
(A D C \text { and } F A)\end{array}$ & $\begin{array}{l}\text { Neural microstruc- } \\
\text { ture and tissue } \\
\text { properties }\end{array}$ & $\begin{array}{l}\text { Degree of diffusivity and } \\
\text { alteration of micro- } \\
\text { structure in correlation } \\
\text { with development, } \\
\text { ageing and interven- } \\
\text { tion }\end{array}$ & $\begin{array}{l}\text { Acute/chronic. } \\
\text { Excellent for } \\
\text { studying the long- } \\
\text { term effects of } \\
\text { early intervention }\end{array}$ & $\begin{array}{c}\text { Good spatial } \\
\text { resolution }\end{array}$ & $\begin{array}{r}0-6 \text { months; } \\
\quad \geq 4 \text { years }\end{array}$ & High & Medium & As given above \\
\hline fMRI & Neuronal function $\left(\mathrm{VO}_{2}\right)$ & $\begin{array}{l}\text { Neural activity in } \\
\text { resting state or } \\
\text { in response to } \\
\text { stimuli }\end{array}$ & Neuronal activation & Acute/chronic & $\begin{array}{l}\text { Low temporal resol- } \\
\text { ution and good } \\
\text { spatial resolution }\end{array}$ & $\begin{array}{r}0-6 \text { months; } \\
\quad \geq 4 \text { years }\end{array}$ & Average & Medium & As given above \\
\hline H-MRS & $\begin{array}{l}\text { Metabolic profile: cre- } \\
\text { atine; lactate; } N \text {-acetyl } \\
\text { aspartate; myoinositol; } \\
\text { choline; glutamate/ } \\
\text { glutamine }\end{array}$ & $\begin{array}{l}\text { Energy metab- } \\
\text { olism; neural } \\
\text { integrity; mem- } \\
\text { brane com- } \\
\text { ponents; neuro- } \\
\text { transmission }\end{array}$ & $\begin{array}{l}\text { Currently exploratory: } \\
\text { changes in brain } \\
\text { metabolism during } \\
\text { development, ageing } \\
\text { and intervention }\end{array}$ & $\begin{array}{l}\text { Probably excellent } \\
\text { for studying the } \\
\text { acute effects of } \\
\text { intervention. Not } \\
\text { clear for long- } \\
\text { term changes }\end{array}$ & $\begin{array}{r}\text { Good temporal and } \\
\text { spatial resolution }\end{array}$ & $\begin{array}{r}0-6 \text { months; } \\
\quad \geq 4 \text { years }\end{array}$ & Average & Medium & As given above \\
\hline P-MRS & $\begin{array}{l}\text { Phosphomonoesters; } \\
\text { phosphodiesters; } \\
\text { phosphocreatine; ATP; } \\
\text { energy phosphates }\end{array}$ & $\begin{array}{l}\text { Neural membrane } \\
\text { formation and } \\
\text { breakdown and } \\
\text { cell energy } \\
\text { metabolism }\end{array}$ & $\begin{array}{l}\text { Currently exploratory: } \\
\text { during development, } \\
\text { ageing and disease, } \\
\text { metabolite changes } \\
\text { measured in }{ }^{31} \text { P-MRS } \\
\text { have been monitored } \\
\text { and normative curves } \\
\text { for normal develop- } \\
\text { ment have been } \\
\text { established }\end{array}$ & $\begin{array}{l}\text { Probably excellent } \\
\text { for studying the } \\
\text { acute effects of } \\
\text { intervention. Not } \\
\text { clear for long- } \\
\text { term changes }\end{array}$ & $\begin{array}{r}\text { Good temporal and } \\
\text { spatial resolution }\end{array}$ & $\begin{array}{r}0-6 \text { months; } \\
\quad \geq 4 \text { years }\end{array}$ & Low & Medium & As given above \\
\hline $\mathrm{EEG} / \mathrm{MEG}$ & $\begin{array}{l}\text { Resting-state brain } \\
\text { activity/ERP/ERF }\end{array}$ & $\begin{array}{l}\text { Electrical curren- } \\
\text { ts/magnetic } \\
\text { fields mainly } \\
\text { generated by } \\
\text { synchronised } \\
\text { activity of corti- } \\
\text { cal neurons }\end{array}$ & $\begin{array}{l}\text { Changes in brain activity } \\
\text { during rest, sensory } \\
\text { stimuli and cognitive } \\
\text { tasks in healthy and } \\
\text { diseased states as } \\
\text { well as during devel- } \\
\text { opment and ageing }\end{array}$ & Acute/chronic & $\begin{array}{l}\text { Very good temporal } \\
\text { resolution and poor } \\
\text { spatial resolution } \\
\text { (standard EEG); } \\
\text { moderate spatial } \\
\text { resolution (high- } \\
\text { resolution EEG) } \\
\text { and high spatial } \\
\text { resolution (MEG) }\end{array}$ & All ages & High & $\begin{array}{l}\text { Low/ } \\
\text { medium }\end{array}$ & $\begin{array}{l}\text { Non-invasive, inexpen- } \\
\text { sive, high temporal } \\
\text { resolution, low-to- } \\
\text { moderate spatial } \\
\text { resolution, highly } \\
\text { translational, neural } \\
\text { correlates of resting } \\
\text { state and cognitive } \\
\text { function }\end{array}$ \\
\hline NIRS & $\begin{array}{l}\text { Oxygenated and deoxy- } \\
\text { genated } \mathrm{Hb} \text { in the } \\
\text { upper layers of the } \\
\text { cortex }\end{array}$ & $\begin{array}{l}\text { Neural activity } \\
\text { and/or simple } \\
\text { cerebral blood } \\
\text { flow and oxy- } \\
\text { genation }\end{array}$ & $\begin{array}{l}\text { Varies with age and } \\
\text { within neurodevelop- } \\
\text { mental and neuro- } \\
\text { pathological groups }\end{array}$ & $\begin{array}{l}\text { Early systems most } \\
\text { suited to acute } \\
\text { studies, but } \\
\text { newer quantitative } \\
\text { systems are well } \\
\text { suited to acute or } \\
\text { chronic designs }\end{array}$ & $\begin{array}{l}\text { Poor spatial resolution } \\
\text { and high temporal } \\
\text { resolution }\end{array}$ & All ages & Low & Low & $\begin{array}{l}\text { NIRS has shown utility } \\
\text { in some relatively } \\
\text { simple nutritional } \\
\text { intervention studies, } \\
\text { and the newer } \\
\text { quantitative systems, } \\
\text { combined with the } \\
\text { employment of } \\
\text { multiple channels, will } \\
\text { make this a practical, } \\
\text { low-cost technique } \\
\text { in future studies }\end{array}$ \\
\hline
\end{tabular}




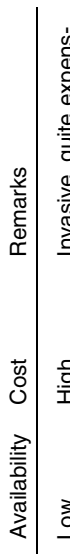

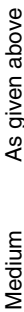

క’

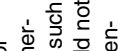

类产 $\frac{0}{5}$

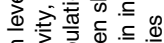

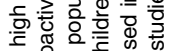

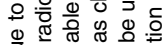

这

든

뜰

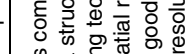

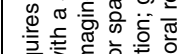

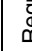

$\llbracket$

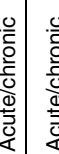

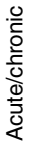

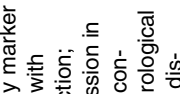

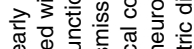

을
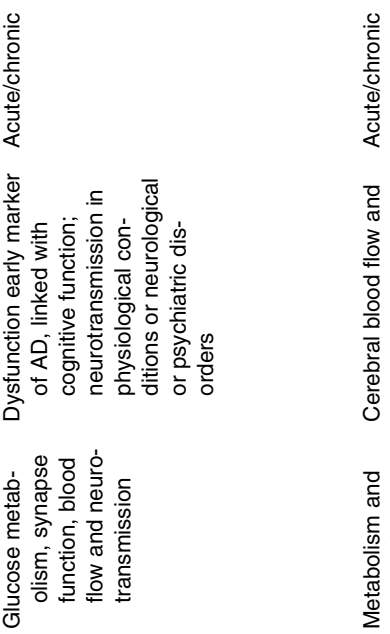

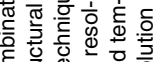
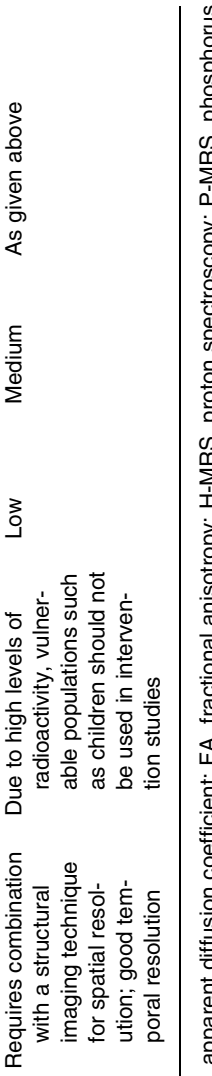

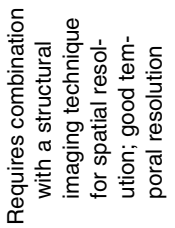

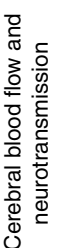

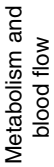

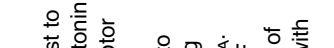

(

क

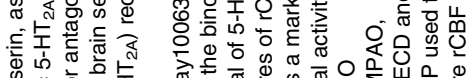

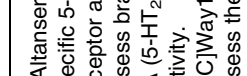

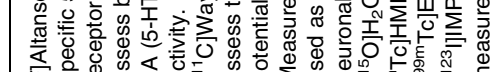

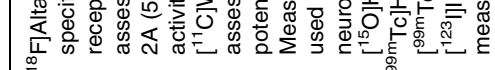

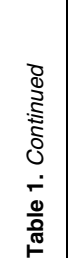

cubic elements called voxels. Most commonly, groups of scans are compared on a voxel-by-voxel basis to determine where significant differences in the concentration, volume and/or density of grey or white matter occur between groups. Voxel-by-voxel correlations with other variables (e.g. behavioural) can also be determined. These analyses produce statistical parameter maps showing where differences between groups (if any) and significant relationships with other variables occur.

Sulcation and gyrification index analysis can be used to assess cortical folding in vivo and to define a sulcation index during development or disease. The analysis uses the white matter and cortical grey matter contrast intensity interface ${ }^{(25)}$. A dramatic increase in the sulcation index, corresponding to brain maturation from an unfolded state to its gyrificated mature state near term, has been demonstrated between 26 and 36 weeks of gestation ${ }^{(25)}$.

Diffusion-weighted imaging/DTI captures microstructural characteristics not apparent in standard anatomical images by utilising the restricted water diffusion in biological brain tissues. Depending on microscopic tissue characteristics (e.g. properties of cell membranes, tissue orientation and myelination), water diffusion will differ by degree and direction. In DTI, a first pulse introduced to the magnetic field determines the initial position of the protons carried by water, while a second pulse detects how far they have moved in space and in which specific direction ${ }^{(26)}$. In this way, we obtain a metric of water diffusion, sensitive to structural characteristics. The number of directions of diffusion measured varies from a minimum of 6 to $>100$.

Several DTI metrics can be applied. Fractional anisotropy (FA) is an intra-voxel index of the degree of diffusion anisotropy (i.e. directionality of diffusion). Several features contribute to FA, including myelin and axonal integrity ${ }^{(27,28)}$, and also complex structural features such as the degree of fibre crossing ${ }^{(29)}$. The constituents of FA are diffusion measured parallel/axial to, and perpendicular/radial to, the principal diffusion direction. In white matter, axial diffusion usually means diffusion along the length of the axon. Any neurobiological inference based on DTI measures must be made with caution, since multiple features influence the metrics ${ }^{(30)}$. However, some hypotheses may be made, depending on the group studied. For instance, to the extent that a nutrient facilitates myelin or axon membrane integrity, one might expect higher FA and lower diffusion measured perpendicular/radial in selected regions in a nutrientfacilitated group. Another commonly used metric is the mean diffusivity, reflecting the degree of diffusivity in any direction. This is an illustration of the tissue microstructure and water content.

There are various ways of evaluating metrics and analysing DTI data. One can delineate tracts of interest or define regions of interest manually, or use automated tools, to conduct voxel-wise statistical analyses of FA, diffusion measured perpendicular/radial, diffusion measured parallel/axial or mean diffusivity data. This can, for example, be done within a white matter skeleton containing only voxels common to 
groups of participants by using tract-based spatial statistics ${ }^{(31)}$, part of the FMRIB Software Library ${ }^{(32)}$ (see Fig. 3 for an example).

MRS proton spectroscopy and phosphorus spectroscopy. The MRS signal produces a spectrum of resonances that correspond to different molecular arrangements of the ${ }^{1} \mathrm{H}$-proton and ${ }^{31} \mathrm{P}$ being excited. ${ }^{1} \mathrm{H}$-MRS and ${ }^{31} \mathrm{P}$-MRS measure different metabolites that are respectively linked to specific brain composition and metabolism (Table 1 ). Because ${ }^{31} \mathrm{P}$ is in lower concentrations in the body than ${ }^{1} \mathrm{H}$, it has a lower signal:noise ratio and therefore a higher magnetic field is required to achieve a better spectral resolution (Fig. 1; Tables 2 and 3). Furthermore, these techniques do require specific hardware. It must be noted that with an increasing magnetic field, spectral resolution is increased, allowing more precise measurements of the targeted metabolites. Both can be used to follow normal metabolic development and to detect disorder-linked metabolic change. ${ }^{1} \mathrm{H}$-MRS allows neural measurements of absolute metabolite concentrations during development, such as choline, creatine, glutamine/glutamate, lactate, myoinositol, macromolecular contributions, $\mathrm{N}$-acetylaspartate (NAA) and taurine ${ }^{(33-35)}$. As gestational age increases, significant increases in NAA, glutamate and glutamine, creatine, taurine levels, with decreases in lactate, myoinositol and phosphoethanolamine levels, have been shown ${ }^{(33,34,36)}$. Regional differences are also present: subcortical areas such as the thalamus showed early high levels of total creatine and NAA, but, by contrast, periventricular white matter showed very little NAA and lactate resonance ${ }^{(33,34,36)}$. In the adult and ageing normal brain, MRS has also been able to characterise MRS-measured metabolite changes with age and region. Mainly, NAA, NAA:choline and NAA:creatine ratios
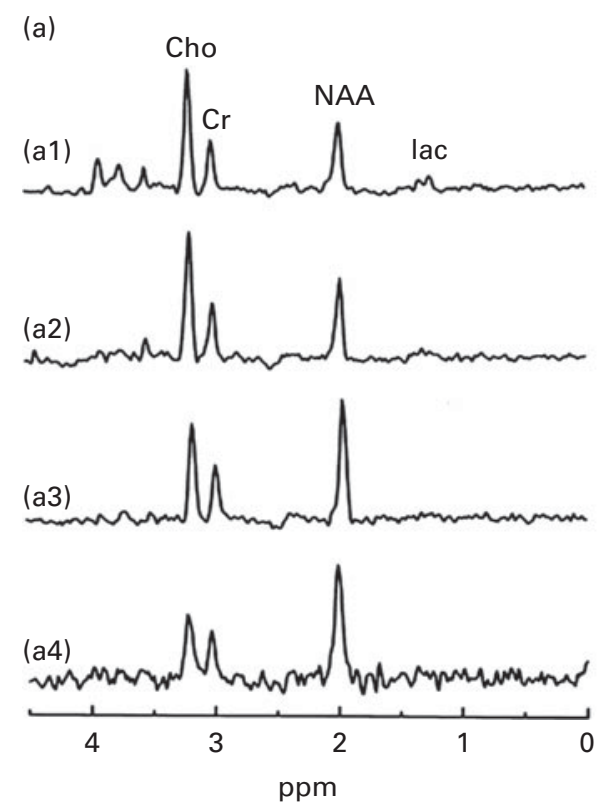

are decreased in the hippocampus as well as in the semioval, temporal and frontal regions in ageing brains ${ }^{(37,38)}$. Furthermore, altered neuronal and glial mitochondrial functions are also present in ageing brains and could be in part linked to brain function decline ${ }^{(39,40)}$. Glutamate, an important neurotransmitter, is reduced in the grey matter of the ageing brain $^{(41,42)}$. White matter tracts also show altered NAA:choline and NAA:creatine ratios for the corpus callosum and splenium $^{(43,44)}$. These changes in grey and white matter metabolism appear to be linked to the reduction of cognition seen in normal ageing ${ }^{(44-46)}$.

${ }^{31} \mathrm{P}$-MRS specifically evaluates energy and phospholipid metabolism by using phosphocreatine, ATP, inorganic phosphate, phosphocholine and phosphoethanolamine measurements ${ }^{(35)}$. In addition, the chemical shift of inorganic phosphate is dependent on intracellular $\mathrm{pH}$, allowing tissue $\mathrm{pH}$ calculation. During development, ageing and disease metabolite changes measured in ${ }^{31} \mathrm{P}$-MRS have been monitored and normative curves for normal development have been established ${ }^{(35,47-51)}$

Functional MRI. Active neurons consume energy for the duration of ongoing processing, resulting in a higher oxygen need and a higher blood flow. This haemodynamic response rises to a peak over $4-5 \mathrm{~s}$, after which it normalises, leading to local changes in the relative concentration of oxygenated $\mathrm{Hb}$ (oxy-Hb) and deoxygenated $\mathrm{Hb}$ (deoxy-Hb) and changes in local cerebral blood volume in addition to this change in local $\mathrm{CBF}^{(52-54)}$. fMRI measures these changes in blood oxygen concentration by recording changes in blood oxygen level-dependent (BOLD) signal. Oxy-Hb is a diamagnetic molecule and becomes paramagnetic when deoxygenated. The

(b)
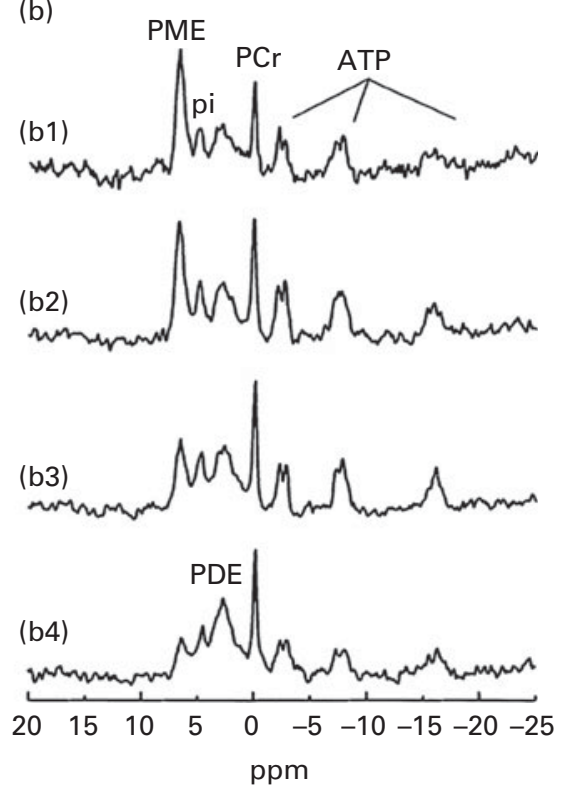

Fig. 1. ${ }^{1} \mathrm{H}-\mathrm{MRS}$ and ${ }^{31} \mathrm{P}-\mathrm{MRS}$ at $1.5 \mathrm{~T}$. (a) Normal typical spectrum of proton spectroscopy of grey matter and changes during brain development. (a1) Normal preterm infant born at 29 weeks of gestation (scan at 35 weeks), (a2) normal-term newborn, (a3) normal infant of 6 months and (a4) normal adult. (b) Normal typical spectrum of ${ }^{31} \mathrm{P}$ spectroscopy of grey matter and changes during brain development. (b1) Normal preterm infant born at 29 weeks of gestation (scan at 35 weeks), (b2) normal-term newborn, (b3) normal infant of 6 months and (b4) normal adult. Cho, choline; Cr, creatine; NAA, N-acetylaspartate; Lac, lactate; PME, phosphomonoesters; Pi, inorganic phosphates; PCr, phosphocreatine; PDE, phosphodiesters; NTP, nucleotide triphosphate. Reproduced from Robertson \& Cox $^{(254)}$. 

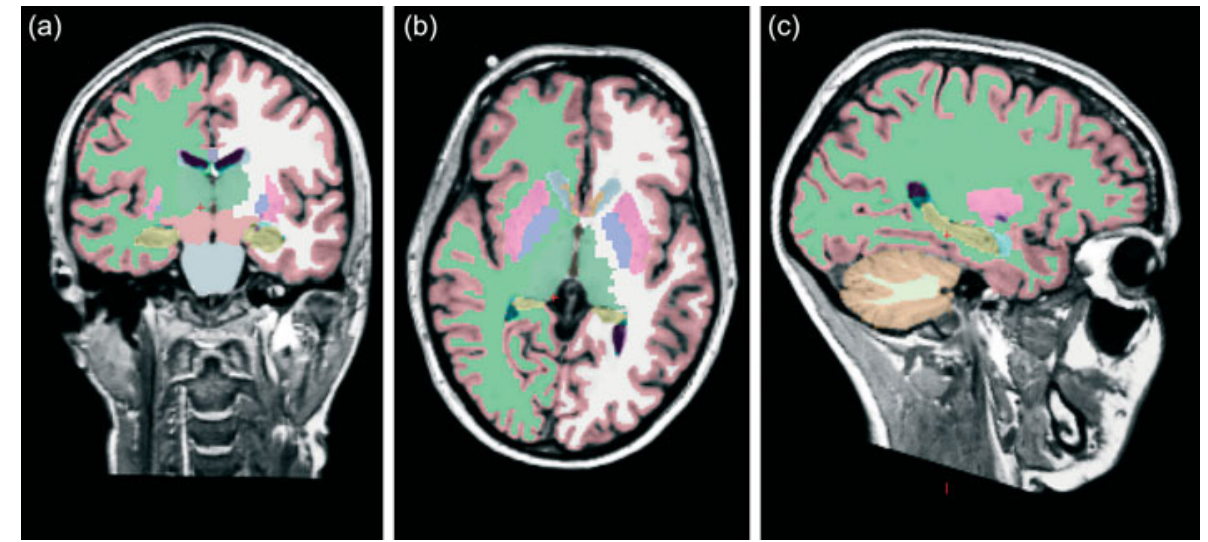

Fig. 2. Whole-brain segmentation of a T1-weighted scan as implemented in FreeSurfer (a brain imaging software package) ${ }^{(24)}$. The segmentation is shown in (a) coronal, (b) horizontal and (c) sagittal views. Each image element (voxel) of the brain volume is labelled as belonging to different structures. For instance, the hippocampus is labelled in yellow.

MR signal of blood is therefore slightly different depending on the level of oxygenation in the local capillaries. These differential signals can be detected using an appropriate MR pulse sequence (i.e. the BOLD signal mentioned previously). Higher BOLD signal intensities arise from decreases in the concentration of deoxy-Hb. These changes can be either positive or negative depending on the relative changes in both $\mathrm{CBF}$ and $\mathrm{VO}_{2}$. Increases in $\mathrm{CBF}$ that exceed changes in $\mathrm{VO}_{2}$ will lead to an increased BOLD signal. In contrast, decreases in $\mathrm{CBF}$ that outstrip changes in $\mathrm{VO}_{2}$ will cause decreased BOLD signal intensity ${ }^{(55)}$.

\section{Eligibility for an MRI examination}

MRI is a non-invasive technique involving the use of magnetic fields and radiofrequency pulses and, hence, no ionising radiation. No clinical side effects have been noted after more than two decades of relatively broad use. As well as making its use in research viable, this also means that scanning can be repeated several times with the same persons, which is important in studying the effects of nutrition on development, ageing or the prevention of disease-related changes.

Although it can be widely used in the population, there are some contraindications to scanning. People with ferromagnetic implants are often unsuitable for scanning as the images would be distorted, and pacemakers will be disturbed by the magnetic field, making scanning not an option for some groups. Dental braces in children may also result in distorted images. Furthermore, persons with claustrophobia or fear of narrow spaces often do not tolerate the typically rather narrow space in the scanner. The ability of a person to avoid moving in the scanner is critical for any type of MR image to be obtained.

An important consideration when using imaging in infants and children is the age at scan acquisition. Until a few months after birth, MRI scanning is fairly accessible and can be performed under natural sleep after feeding. In naturally sleeping infants, fMRI can be performed and resting-state activity, as well as response to light, auditive and smell stimulation, can be measured. For older children, the sequences used in structural imaging and DTI can be made quite short, often less than $10 \mathrm{~min}$. However, this may still be a long
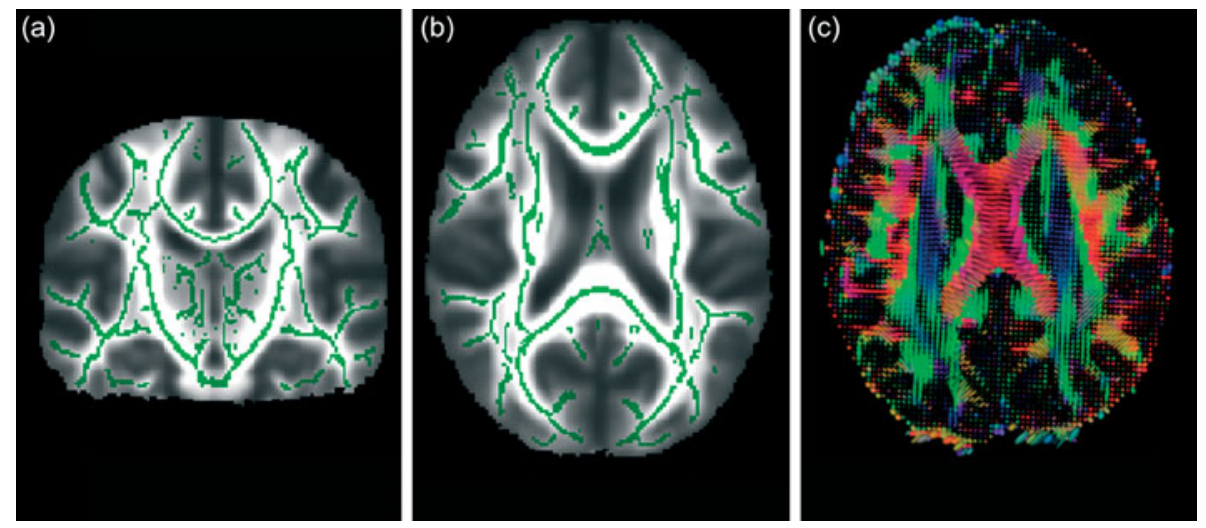

Fig. 3. From diffusion tensor imaging, measures of fractional anisotropy (FA) can be derived. Areas of higher diffusion directionality, or FA, are shown in a lighter colour (a) coronally and (b) horizontally. The white matter skeleton created by tract-based spatial statistics as implemented in FSL ${ }^{(41)}$ contains only tract voxels common to all participants in a study and is shown here in green imposed on the FA volume. To the right (c), the direction of diffusion in different parts of the brain is shown colour coded. Red colour denotes diffusion along the medial-lateral axis (such as in the corpus callosum connecting the hemispheres). Green colour denotes diffusion along the posterior-anterior axis, while blue colour denotes diffusion along the inferior-superior axis. 
Table 2. Absolute concentrations of brain metabolites in individuals of different age groups in $\mathrm{mmol} / \mathrm{kg}$ brain tissue and significance tests for differences found ${ }^{*}$

(Mean values with their standard errors)

\begin{tabular}{|c|c|c|c|c|c|c|c|c|c|c|c|c|c|}
\hline \multirow[b]{2}{*}{ Groups } & \multirow{2}{*}{$\mathrm{ROI}(n)$} & \multicolumn{2}{|c|}{ GA (weeks) } & \multicolumn{2}{|c|}{$\begin{array}{c}\text { pn age } \\
\text { (weeks) }\end{array}$} & \multicolumn{2}{|c|}{ NAA } & \multicolumn{2}{|c|}{$\mathrm{Cr}$} & \multicolumn{2}{|c|}{ Cho } & \multicolumn{2}{|c|}{$\mathrm{ml}$} \\
\hline & & Mean & SEM & Mean & SEM & Mean & SEM & Mean & SEM & Mean & SEM & Mean & SEM \\
\hline$<42 \mathrm{GA}$ & 11 & $38 \cdot 7$ & 0.7 & 3.9 & 1.6 & $4 \cdot 82 \mathrm{a}$ & 0.54 & $6 \cdot 33$ & 0.32 & $2 \cdot 41$ & 0.11 & $10 \cdot 0$ & $1 \cdot 1$ \\
\hline $42-60 \mathrm{GA}$ & 8 & $50 \cdot 2$ & 1.8 & $9 \cdot 3$ & 1.9 & 7.03 & 0.41 & $7 \cdot 28$ & 0.28 & $2 \cdot 23$ & 0.06 & 8.52 & 0.92 \\
\hline$<2 \mathrm{pn}$ & 6 & $40 \cdot 0$ & 1.0 & 0.8 & 0.2 & 5.52 & 0.64 & 6.74 & 0.43 & 2.53 & 0.12 & $12 \cdot 4$ & 1.4 \\
\hline $2-10 \mathrm{pn}$ & 7 & 41.9 & 1.5 & 3.8 & 0.9 & $5 \cdot 89$ & 0.21 & $6 \cdot 56$ & 0.44 & $2 \cdot 16$ & 0.09 & $7 \cdot 69$ & 0.62 \\
\hline Adult & 10 & & & 1440 & 68 & 8.89 & 0.17 & 7.49 & $0 \cdot 12$ & 1.32 & 0.07 & 6.56 & 0.43 \\
\hline \multicolumn{14}{|l|}{$P$} \\
\hline \multirow{2}{*}{\multicolumn{6}{|c|}{$<42 \mathrm{GA} v$. adult }} & \multicolumn{2}{|c|}{$<0.0001$} & \multicolumn{2}{|c|}{$<0.0001$} & \multirow{2}{*}{\multicolumn{2}{|c|}{$\begin{array}{c}<0.0001 \\
0.07\end{array}$}} & \multicolumn{2}{|c|}{0.001} \\
\hline & & & & & & \multicolumn{2}{|c|}{0.0007} & \multicolumn{2}{|c|}{0.02} & & & \multicolumn{2}{|c|}{0.10} \\
\hline $42-60$ GA $v$. adult & & & & & & \multirow{2}{*}{\multicolumn{2}{|c|}{$<0.0001$}} & \multirow{2}{*}{\multicolumn{2}{|c|}{$\begin{array}{c}0.16 \\
0.005\end{array}$}} & \multicolumn{2}{|c|}{$\begin{array}{c}0.07 \\
<0.0001\end{array}$} & 0.0 & \\
\hline $42-602$ pn $v$. adult & & & & & & & & & & \multicolumn{2}{|c|}{$<0.0001$} & \multicolumn{2}{|c|}{$<0.0001$} \\
\hline 2 pn v. $2-10$ pn & & & & & & \multicolumn{2}{|c|}{0.7} & \multicolumn{2}{|c|}{0.8} & \multicolumn{2}{|c|}{0.02} & \multicolumn{2}{|c|}{0.004} \\
\hline $2-10 \mathrm{GA} v$. adult & & & & & & \multicolumn{2}{|c|}{$<0.0001$} & \multicolumn{2}{|c|}{0.001} & \multicolumn{2}{|c|}{$<0.0001$} & \multicolumn{2}{|c|}{0.007} \\
\hline
\end{tabular}

$\mathrm{ROI}$, region of interest; GA, gestational age; pn, postnatal age; NAA, $\mathrm{N}$-acetylaspartate; $\mathrm{Cr}$, creatine; Cho, choline.

${ }^{*}$ Reproduced from Ross \& Bluml ${ }^{(35)}$.

time for young children to keep still and the option of sedation is only warranted in the case of clinical scans. The success rate may increase in school-aged children. Some centres use pre-scan training in a mocked-up scanner to reduce the age limit of viability. To enhance cooperation, audio books/ music can be played at the time of scan, and if the equipment allows, cartoons may be projected or viewed in special goggles. For fMRI studies, stimuli-response paradigms have to be adapted to the age of the children and their ability to understand the task. Using MRI in the early years of childhood is difficult but important due to the fact that great brain development is ongoing during childhood and MRI could thus provide crucial information on the effects of nutrition during brain development. The plasticity of the brain during this period indicates that it may be a likely time for nutrition to influence structural changes. Studies that have followed up subjects after early dietary intervention, however, have shown that the effects tend to persist over time ${ }^{(3,56)}$; thus, brain scans obtained later in childhood may still be informative.

From a broader point of view, due to reasons described above, neuroimaging studies should include uniform samples with regard to the age or, if subjects who vary widely in age are included, age at the scan should be used as a covariate in analyses. This is particularly true in childhood, in which the development occurs over a relatively short time span.

\section{Use of MRI in nutritional studies}

Past nutritional studies that have used MRI techniques. If we discount studies in clinical populations, the number of nutritional intervention studies using imaging measures is minimal. This is not surprising since it has been unusual in the past for research centres to collect both the nutritional and MRI data necessary to conduct these studies, but a few reports have started to appear. Nutritional studies tend to concentrate on the two extremes of the age spectrum, infancy and old age, periods in life with relatively large changes in brain morphology and functionality. There is, however, a difference in emphasis between the two. While studies in children have investigated whether different nutrition regimens can enhance brain development, studies in adults have tended to focus on whether diet and nutrients may act to protect the brain from age-associated atrophy or disease. It is important to keep in mind that structural changes may not correspond directly to changes in function and that such structural changes may bias the results. Grey matter atrophy and sulcal expansion in older adults may be responsible for a great anatomical variability between the brains of younger and older adults and

Table 3. Concentrations of ${ }^{31} \mathrm{P}$ metabolites in healthy brains of human neonates, infants and adults $\dagger$ (Mean values and standard deviations)

Concentration $\left(\mathrm{mmol} / \mathrm{l}=\mathrm{mmol} / \mathrm{dm}^{3}\right)$

\begin{tabular}{|c|c|c|c|c|c|c|c|c|c|c|c|c|c|}
\hline & \multirow[b]{2}{*}{$n$} & \multicolumn{2}{|c|}{ PME } & \multicolumn{2}{|c|}{$\mathrm{Pi}$} & \multicolumn{2}{|c|}{ PDE } & \multicolumn{2}{|c|}{$\mathrm{PCr}$} & \multicolumn{2}{|c|}{ ATP } & \multicolumn{2}{|c|}{${ }^{31} \mathrm{P}$ total } \\
\hline & & Mean & SD & Mean & SD & Mean & SD & Mean & SD & Mean & SD & Mean & SD \\
\hline Neonates & 16 & $4 \cdot 5^{\star \star}$ & 0.7 & $0 \cdot 6^{\star \star \star}$ & 0.1 & $3 \cdot 2^{\star \star \star}$ & 0.8 & $1.4^{\star \star \star}$ & 0.2 & $1 \cdot 6^{\star \star \star}$ & 0.2 & $14 \cdot 9^{\star \star \star}$ & $2 \cdot 3$ \\
\hline Infants & 17 & 3.6 & 0.9 & 0.6 & $0 \cdot 1$ & $4 \cdot 2$ & 0.7 & $1 \cdot 7$ & 0.3 & $1 \cdot 8$ & 0.3 & $16 \cdot 1$ & $2 \cdot 5$ \\
\hline Adults & 28 & $3 \cdot 5^{\star \star}$ & 0.6 & $1 \cdot 0^{\star \star \star}$ & 0.2 & $11 \cdot 7^{\star \star \star}$ & $2 \cdot 2$ & $3 \cdot 4^{\star \star \star}$ & 0.5 & $2 \cdot 9^{\star \star \star}$ & 0.4 & $29 \cdot 3^{\star \star \star}$ & $3 \cdot 1$ \\
\hline
\end{tabular}

PME, phosphomonoesters; Pi, inorganic phosphates; PDE, phosphodiesters; PCr, phosphocreatine.

Mean values are significantly different: ${ }^{\star \star} P<0.01,{ }^{\star \star \star} P<0.001$.

$\dagger$ Reproduced from Buchli et al. ${ }^{(255)}$. 
within a single random sample of older individuals ${ }^{(57,58)}$. Therefore, it is important to define structure-function relationships. Some examples of studies are presented below.

$M R I$ studies of altered nutrition during fetal life: effects on the brain during intrauterine growth retardation. Threedimensional MRI has been used to evaluate the effects of intrauterine growth retardation (IUGR) on brain development. IUGR can be considered as inadequate nutritional supply during pregnancy. Preterm IUGR infants show altered brain development with reduced cortical grey volumes ${ }^{(59)}$, hippocampal volumes ${ }^{(60)}$ and sulcation index ${ }^{(61)}$ compared with normally grown preterm infants. These changes are correlated with altered neurodevelopmental scores. Thus, early cortical development seems to be modified by altered intrauterine nutritional environment ${ }^{(61)}$.

DTI has also been used to assess the effects of IUGR on the microstructural development of the brain. Results have shown a higher apparent diffusion coefficient value in the internal capsule of IUGR infants at birth compared with that of nonIUGR infants. This change persists at term, indicating reduced maturation in this area, which represents a major white matter fibre tract that normally myelinates between 34 and 40 weeks of gestational age. Further results have indicated reduced relative anisotropy with a less well-developed fibre tract system at birth in the corpus callosum, the main interhemispheric connection system ${ }^{(62)}$. VBM has verified these findings by revealing similar regions of microstructural changes in IUGR preterm infants when compared with control groups ${ }^{(63,64)}$. ${ }^{1}$ H-MRS has shown altered metabolites in grey and white matter in preterm infants with $\operatorname{IUGR}^{(64,65)}$. In grey matter, NAA and myoinositol levels were reduced in the compromised group and energy supply alteration with increased creatine levels could also be measured. In white matter, similar alterations were present in infants with IUGR; in addition, an increased level of lactate was found, indicating altered metabolism, possibly due to astrocyte metabolism changes.

$M R I$ studies of nutritional effects on the brain in children. Very few reports exist, but a study by Taki et al. ${ }^{(66)}$ has illustrated how MRI could be used. The authors divided 290 healthy 11-year-old children into three groups, depending on their breakfast staple (rice, bread or both), and used VBM to look for differences in grey and white matter and also compared intelligence quotient (IQ) measures among the groups, incorporating covariates such as socio-economic class and age. Differences in both overall and regional grey and white matter volumes among the groups have been reported as well as a significant advantage for the rice group in the Perceptual Organisation Index Score of the IQ test. The glycaemic index has been suggested as a possible explanatory mechanism.

The best evidence for nutritional effects on the brain would be to obtain MR images as an outcome measure for children who had taken part in an earlier randomised controlled trial of a nutritional intervention. For instance, two studies have reported structural and cognitive outcomes at adolescence in a subgroup of a cohort of preterm infants (all neurologically normal) who had taken part in a randomised feeding trial perinatally ${ }^{(67)}$. In one study, a high-nutrient diet was associated with larger volumes of the caudate nuclei and a higher verbal IQ, but only in boys ${ }^{(68)}$. In a later report, the percentage of maternal breast milk in the infant diet was associated with a greater white matter volume and a higher verbal IQ; again, the effects were stronger in boys ${ }^{(69)}$.

VBM has been used to demonstrate relationships between regional brain volumes and $\mathrm{IQ}^{(70)}$ as well as more specific cognitive functions such as reading ${ }^{(71)}$, calculation ${ }^{(72)}$ and executive function ${ }^{(73)}$. Likewise, other techniques, both whole-brain segmentation and surface reconstruction, yielding volumetric and cortical thickness measures, have also shown sensitivity to differences in cognitive and behavioural functions. These techniques could therefore be used to explore whether a nutritional intervention affects such outcomes.

MRI studies of nutritional effects on the brain in adults. There are multiple mechanisms by which nutrients or supplements may serve to protect the ageing brain ${ }^{(74,75)}$, including by lowering cerebrovascular disease, inflammation and/or oxidation. A recent, large study of elderly subjects has shown associations between image measures of brain health and cognitive function, on the one hand, and plasma biomarkers of vitamin and fatty acid status and trans-fat, on the other hand ${ }^{(76)}$.

There is much literature showing that elevated homocysteine levels are negatively related to cognitive function in ageing $^{(77-80)}$ with good indications from MRI studies that the cognitive effects may be mediated through brain atrophy, hyperintensities and/or subclinical infarcts ${ }^{(79,81-83)}$. Still, it may be that elevated homocysteine levels are not a causal mechanism for brain atrophy and cognitive deterioration, but rather a by-product. However, this possibility has recently been weakened by a large well-controlled intervention study ${ }^{(84)}$. The study was a randomised double-blind controlled trial using high-dose folic acid and B vitamins in persons aged $>70$ years and categorised as having mild cognitive impairment. MRI scans were performed at the start and end of the study after 2 years. The mean rate of brain atrophy per year was significantly lower in the treatment group than in the placebo group and the treatment response was related to baseline homocysteine levels. The greater rate of atrophy in the placebo group, primarily seen in the images as an enlargement of the ventricles, was associated with a lower final cognitive test score (Mini-Mental State Examination and Telephone Interview of Cognitive Status).

A recent study on long-chain PUFA (LC-PUFA) has shown that among older adults, dietary intake of fish with a higher EPA and DHA content was associated with a lower prevalence of subclinical infarcts and white matter abnormalities on MRI examinations ${ }^{(76,85,86)}$. This finding was extended by the observation that in middle-aged adults, DHA, but not EPA or $\alpha$-linolenic acid, in serum, was associated with improved non-verbal reasoning, working memory and vocabulary ${ }^{(86)}$.

Choline, a precursor of acetylcholine and phosphatidylcholine, is important for brain metabolism and is largely obtained from the diet. Cohen et $a l^{\left({ }^{(8)}\right)}$ measured plasma and brain choline levels with ${ }^{1} \mathrm{H}$-MRS after a single choline supplement in young and aged healthy subjects. The results showed that despite a similar choline increase in plasma in 
both groups, the brain levels of choline measured by ${ }^{1} \mathrm{H}-\mathrm{MRS}$ were lower in the aged group, indicating a decrease in choline uptake into the brain with age ${ }^{(87)}$. Given the role of choline in cholinergic neuronal function, the reduced uptake of choline may be involved in altered brain function in the elderly and in neurodegeneration. Similarly, in a study on healthy adults using ${ }^{31} \mathrm{P}-\mathrm{MRS}$, administration of uridine appeared to increase brain membrane precursors (phosphomonoesters: phosphocholine and phosphoethanolamine $)^{(88)}$. Furthermore, studies have shown altered membrane phospholipids and fatty acid metabolisms in psychiatric or epileptic diseases using ${ }^{1} \mathrm{H}-\mathrm{MRS}$ and ${ }^{31} \mathrm{P}$ $\mathrm{MRS}^{(89,90)}$. It has also been reported that citicoline improves frontal lobe bioenergetics and alters phospholipid membrane turnover. It may therefore help to mitigate cognitive declines associated with ageing by increasing energy reserves and utilisation, as well as increasing the amount of essential phospholipid membrane components needed to synthesise and maintain cell membranes ${ }^{(91)}$. In psychotic adults, ethyl-EPA supplementation appears to improve symptoms in relation to an increase in brain glutathione levels and glutamate:glutamine ratio measured by ${ }^{1} \mathrm{H}-\mathrm{MRS}$, which can be linked to improved antioxidative defence through astrocyte metabolism ${ }^{(92)}$.

In the last few years, fMRI has been used to investigate the mechanisms related to the physiological or pathological regulation of food intake, as well as the cognitive/affective processing of food-related stimuli ${ }^{(93)}$. These studies have identified a food-related functional recruitment in both sensory processing and emotion-related structures, including prefrontal, orbitofrontal temporal and cingulate regions, amygdala and insula. Nonetheless, few fMRI studies have tried to determine the role of nutrition in brain function. Recently, fMRI has been used to examine the effect of nutrition in young healthy volunteers who had a breakfast including various nutrients (i.e. food containing proteins, lipids, vitamins and minerals as well as carbohydrates) when compared with when they skipped breakfast or had only sugar for breakfast ${ }^{(94)}$. When participants were performing memory and attention tasks, significantly higher brain activation was observed in the medial prefrontal areas, but only following the nutritionally balanced breakfast.

\section{Methodological limitations and recommendations of relevance to intervention studies}

Any effects of nutrition found by MRI studies will need to be interpreted with care. Ideally, all of the scans for one study should be obtained using the same scanner and the same imaging protocol, because variations can complicate the interpretation of results. However, this is often not feasible in large-scale studies, and therefore standardised protocols across sites and scanner platforms allow data to be pooled. This can greatly increase the number of subjects and hence possible analyses. In recognition of this, multi-site initiatives, such as the Alzheimer's Disease Neuroimaging Study (http:// www.adni-info.org/), have been launched in recent years, indicating that consistent and valuable results can be obtained across sites and platforms ${ }^{(95)}$. With standardisation criteria carefully being tested and employed, multi-site initiatives can be highly powerful.

Findings from structural studies can be used to illustrate the complexities of linking structure to function. It is well known that a reduction of MRI-derived volume is often observed along with diminished cognitive function in injury or central nervous system (CNS) disorders, such as Alzheimer's disease (AD). However, while a 'bigger is better' view has sometimes been supported in the study of relationships between normal brain structures and cognitive abilities, this is not likely to hold independently of groups studied ${ }^{(96)}$. For instance, a decrease in cortical thickness is seen with increased cognitive function in school-aged children ${ }^{(97,98)}$, yielding a negative correlation of cortical thickness and cognitive performance scores, whereas a shift in the direction of this relationship is seen during ageing $^{(99-101)}$, with thinner cortices usually being accompanied by some reduction of cognitive speed performance scores. This probably occurs because in children, cognitive development is enhanced by pruning or fine-tuning of synaptic connection, along with intracortical myelination, processes that would make the cortex appear thinner in MR images. On the other hand, during ageing, loss of synaptic spines and synapses, as well as neuronal shrinkage and possible neuronal loss, would decrease both cortical thickness and cognitive function. Thus, the relationship between volumetric/cortical surface characteristics and cognitive outcome is not constant throughout life.

Due to the high sensitivity of MRI to blood flow, it is crucial to recognise that not all interventions leading to a change in the BOLD signal may necessarily also lead to a perceivable behavioural change in examined subjects ${ }^{(102)}$. Nonetheless, several studies have identified an association between blood flow and metabolic rate, suggesting that the blood supply is tightly regulated in space and time to provide the nutrients for brain metabolism ${ }^{(103)}$. Importantly, structure-function relationships need to be defined to better understand disease- or nutrition-induced changes. This can be done using a stimulus-response paradigm and correlation with structural changes.

Furthermore, alterations in cognitive function due to ageing may depend on the specific task or function explored and may vary from one brain region to another. It is known, for example, that brain activity may be reduced in older persons when compared with younger individuals in prefrontal cortex $^{(104)}$ or medial temporal areas ${ }^{(105)}$ during different memory tasks. On the other hand, an over-recruitment of the prefrontal cortex has often been described in older healthy subjects during execution of various cognitive tasks ${ }^{(106)}$. Therefore, participant selection and screening may be fundamental in cross-section evaluations ${ }^{(107)}$. For instance, the inclusion of relatively high-functioning elderly individuals may bias the cross-sectional results in such a way that the cross-sectional analyses indicate an over-recruitment of the dorsal frontal cortex, while the longitudinal analysis reveals an age-related activity reduction in the same frontal regions ${ }^{(107)}$.

Structural and functional data transformations should be carefully verified and, when available, population-specific templates should be used to optimise alignment and reduce distortions ${ }^{(108)}$. However, it is important that the variability 
between standard templates and the study group is not too great. For example, it is necessary to take age into account, especially when studying infant brains, which differ a great deal in terms of gross morphometric features from those of older children and adults. Intracranial volume and brain size undergo dramatic changes in the first few years of life, and slight changes are also seen throughout the teens, but the overall intracranial and brain volume in school-age years is very similar to that of adults ${ }^{(109)}$ and standard templates may be used. Moreover, some classification, averaging and matching techniques used employ procedures shown to be well suited to account for varying anatomies ${ }^{(110)}$.

When fMRI is used to study brain functional organisation in individuals of different ages, it is important to take into consideration that methods for fMRI data analysis are exquisitely sensitive to blood flow. This means that cerebrovascular changes associated with ageing could alter one or more parameters of the vascular regulation ${ }^{(111)}$ and hence the results. For instance, studies that evaluated the visual cortex response during passive stimulation have reported a decreased fMRI signal in older adults when compared with younger individuals $^{(112,113)}$, and this was not caused by reduced neural activity, but rather by differences in neurovascular local properties $^{(114)}$. One or more valid control tasks should be used as age-related differences in neurovascular response should influence all conditions equally. Thus, an evaluation of the size of the within-group effect should be safer than a direct comparison of the BOLD signal change in two age groups ${ }^{(115)}$. Other possible solution is the normalisation of the task-related signal change by the use of breath-holding to produce global changes in BOLD signal ${ }^{(116)}$ or with a simple sensory or motor task to estimate the haemodynamic response function for each individual included in the study ${ }^{(117)}$

We discuss here some of the issues pertinent to the consumption of supplements ${ }^{(84)}$, mostly using examples on homocysteine. While the literature linking homocysteine levels to brain measures is impressive, some inconsistencies and nuances of general relevance to possible nutritional intervention studies should be mentioned.

Age at intervention. First, since relationships between neuroimaging markers and nutrition indicators in adulthood have mostly been studied in middle-aged and older individuals, it is unknown whether relationships exist throughout the adult lifespan or at which point they may occur. The relationship between homocysteine levels and cognitive function was confined to adults aged $\geq 60$ years in a large-scale study ${ }^{(80)}$. To the extent that nutrients are tested for a protective effect, they should be studied at an age span in which negative influences come into play (i.e. at a stage where age-associated atrophy has accumulated or become more marked or diseaserelated changes are more likely to set in).

Sex effects. There is some indication that relationships may be stronger in men ${ }^{(83)}$. This is not established enough to justify targeting only men for nutritional interventions, but intervention studies need to be sufficiently powered to analyse sex effects. Since evidence for sex effects has also been found in early intervention studies ${ }^{(68,69)}$, it is probably informative to include planned analyses by sex in all nutritional studies.
Use of multimodal imaging markers. While many studies have found effects of nutrition indicators on the brain, the particular measures that show effects may vary and are not always consistent across studies. For instance, while many studies on homocysteine levels have found effects on atrophy, one study has found no effect on atrophy, but only an effect on white matter hyperintensities ${ }^{(83)}$. Similarly, a recent study has reported associations between total cerebral brain volume and biomarkers of vitamin (positive) and trans-fat (negative), while fatty acid biomarkers have been reported to be related only to white matter hyperintensities ${ }^{(76)}$. This points to the importance of including multiple imaging measures. In addition, in line with recent studies pointing to the unique explanatory power of different imaging modalities relative to each other ${ }^{(118)}$, one should include several types of scans with respect to outcome measures (e.g. T1 weighted, T2 weighted, DTI and MRS).

Regional neuroanatomical specificity of effects. To the extent that hypotheses can be made a priori, studies should use analysis techniques that allow for testing effects located in specific brain systems. For instance, if fatty acids are hypothesised to affect the fibre integrity or myelination of major white matter tracts, DTI measures sensitive to this may be employed. It has been suggested that some discrepancies in the literature regarding the effects of $\mathrm{B}_{6}$ and $\mathrm{B}_{12}$ vitamins and folic acid, and by implication, homocysteine levels, may stem from differences in the sensitivity of image analysis techniques, where global measures of brain volumes will not necessarily capture regionally specific effects ${ }^{(119)}$. In a small study using diet diaries, evidence has been found for medial volumetric effects, including anterior cingulate and parietal areas, as well as temporal and superior frontal effects of $\mathrm{B}_{6}$ and $\mathrm{B}_{12}$ vitamin and folic acid supplement intake. Hence, studies should include analyses sensitive to localised neuroanatomical effects ${ }^{(119)}$.

\section{Electroencephalography and magnetoencephalography: measuring brain electrical and magnetic activities}

\section{Electroencephalography and magnetoencephalography techniques and electroencephalography/ magnetoencephalography-derived measures}

EEG and MEG measure brain electrical and magnetic activities recorded from scalp electrodes and extracranial sensors, respectively. Scalp EEG activity is recorded as a voltage difference; thus, different reference derivations provide diverse voltage values at exploring electrodes. The general procedure for the recording of scalp EEG activity involves the positioning of an elastic cap with cabled cup electrodes or single-cup electrodes in standardised locations of the scalp. EEG procedures are especially suitable for multicentric studies, since EEG systems are always present in neurological departments and the EEG data of different recording systems can be harmonised using calibration signals of a defined voltage amplitude (i.e. $100 \mu \mathrm{V}$ ).

MEG activity is a reference-free measure recorded by superconducting quantum interference devices, which are sensors able to transform very small magnetic fields into recordable currents. The general procedure for the recording 
of extracranial MEG activity involves the demagnetisation of the subject and positioning of his or her head under a helmet with superconducting quantum interference devices. As a main merit, EEG and MEG signals have the highest temporal resolution compared with all the current brain imaging techniques (i.e. they can measure the amplitude of brain electromagnetic activity with a sampling $<1 \mathrm{~ms}$ ).

From a physiological point of view, EEG and MEG signals derive from the post-synaptic ionic currents of synchronously active pyramidal neurons over extended cortical regions $(\mathrm{cm})$ and reflect the integrative information processing of signals originating in the thalamus, brainstem and other cortical modules. In these extended cortical regions, both tangentially and radially oriented sources produce most of the scalp EEG signals, whereas only tangential sources produce MEG signals. It is noteworthy that EEG is characterised by a low spatial resolution (i.e. the ability to localise the cortical source of scalp EEG activity within several centimetres), since different conductivities of head tissues (brain, meninges, skull and scalp) attenuate and blur the spatial distribution of neural currents from brain sources to scalp electrodes. To minimise these weakness points, EEG activity can be recorded from 48 to 128 electrodes and can be processed to obtain reference-free and spatially deblurred EEG activity. This can enhance the spatial resolution of EEG to a few centimetres and eliminate the need for a reference. With respect to EEG, the spatial resolution of MEG is higher (several millimetres in the best experimental conditions, namely simple evoked magnetic fields), since magnetic fields are not affected by different conductivities of brain, skull and scalp tissues.

The high temporal resolution of EEG and MEG signals is ideal for investigating the emerging features of brain physiology, namely awake resting-state brain rhythms. In this condition, the subjects are minimally affected by anxiety, fatigue and issues related to their cognitive-motor performance (task difficulty, meta-learning, etc.). It is also ideal for investigating immediate brain responses to sensory, cognitive or motor events in short-term (acute) and long-term (chronic) intervention studies. Spectral analysis methods allow the estimation of EEG and MEG dynamics in terms of the dominant frequencies, power (or amplitude), phase and coherence of EEG rhythms. The background spontaneous oscillatory activity of brain neurons at about $10 \mathrm{~Hz}$ generates the dominant alpha rhythm of resting-state EEG and MEG activities ${ }^{(120)}$. Oscillations in other frequency bands, such as $\delta(1-4 \mathrm{~Hz}), \theta(4-7 \mathrm{~Hz})$ and $\gamma(30-$ $70 \mathrm{~Hz}$ ) bands, also exhibit complex patterns of power that are modulated by cognitive processes such as attention, perceptual binding and working memory ${ }^{(121)}$. On the other hand, EEG and MEG techniques can be used to study the fine timing (millisecond scale) of event-related or evoked cortical responses to external stimuli, mental operations or movements (Fig. 4). Functional connectivity between brain areas is crucial for perceptual and cognitive processes that are intrinsically based on the integration of information represented in several cortical and subcortical areas in the human brain. Both resting-state and the mentioned event-related EEG/MEG measures can be used as input for the evaluation of functional connectivity of brain networks. Spectral coherence (linear), directed transfer function (linear) and synchronisation likelihood (linear and nonlinear) techniques are typically used to do so from EEG/MEG rhythms recorded during resting-state conditions, while event-related covariance can be used from event-related potentials (ERP)/ event-related fields ${ }^{(122)}$. The choice between EEG and MEG techniques depends on the importance of spatial resolution for testing the working hypothesis (effects of the intervention on specific cortical regions).

\section{Eligibility for an electroencephalography/ magnetoencephalography examination}

EEG/MEG recordings are fully non-invasive and technically easy procedures that can be easily repeated several times in human subjects of any age (i.e. from newborns to elderly people) and clinical status (i.e. patients in a coma or a vegetative state) without 'repetition' effects. It has been shown that EEG variables correlate with individual subjects' cognitive state and specific intellectual abilities (e.g. reading) during child development, including individuals with Down

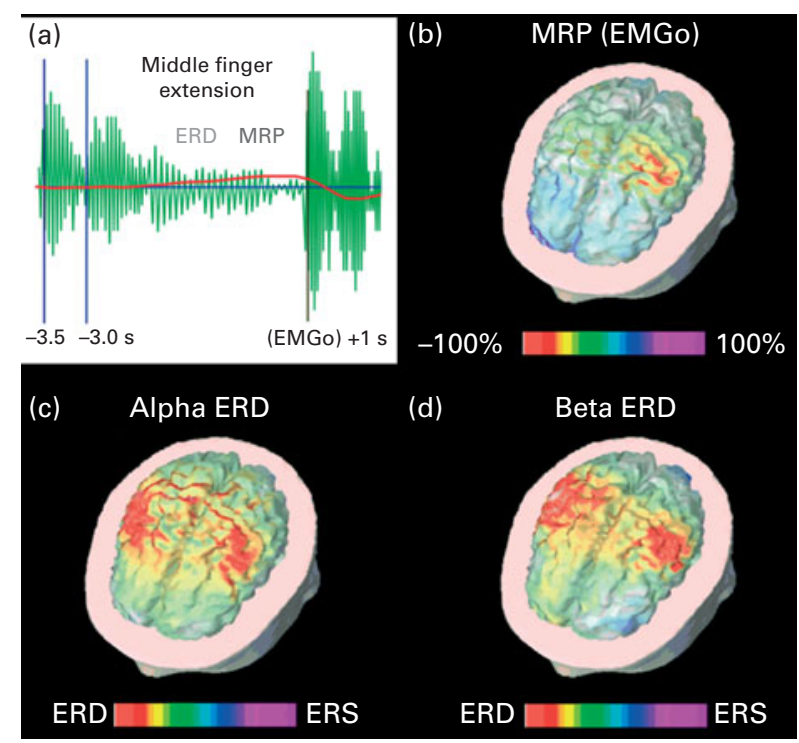

Fig. 4. Analysis in the time and frequency domains of electroencephalographic (EEG) data related to a motor event (i.e. voluntary self-paced right middle finger extensions). (a) A schematic representation of ongoing EEG rhythms at $\alpha$ frequencies (about $10 \mathrm{~Hz}$ ) before, during and after the onset of the electromyographic (EMGo) activity associated with voluntary self-paced middle finger extensions. It can be seen that the amplitude of alpha rhythms is reduced during the preparation and execution of the movement, the socalled alpha event-related desynchronisation (ERD) and is enhanced after the EMGo, the so-called event-related synchronisation (ERS). In the same dataset, a slow negative shift is hidden in the EEG oscillations, namely the movement event-related potentials (MRP). The example shows that the same EEG dataset can be analysed in the frequency domain to compute the alpha ERD and in the time domain to produce MRP. (b) A topographic map showing cortical sources of the MRP as computed by a weighted, minimum-norm linear inverse estimation. It can be noted that the maximum source amplitude (red hot spot) is represented in the Rolandic region of the left hemisphere contralateral to the movement side. (c, d) Topographic maps showing cortical sources of the ERD at $\alpha$ (about $10 \mathrm{~Hz}$ ) and $\beta$ (about $20 \mathrm{~Hz}$ ) frequencies. With respect to the MRP, alpha and beta ERD were characterised by maximum source amplitude (red hot spots) in the Rolandic regions of both hemispheres. It is concluded that quantitative EEG techniques can reveal parallel physiological processes underlying the activation of sensorimotor cortical regions related to voluntary movements. 
syndrome ${ }^{(123)}$; overweight or underweight adults ${ }^{(124,125)}$; and patients with disorders of vigilance, consciousness and communication $^{(126,127)}$; as well as elderly subjects with intact cognitive status or cognitive decline progressing to overt dementia $^{(128-134)}$. Such a correlation is typically moderate and emerges with relatively large populations $(n>30)$ and a fine clinical and neuropsychological assessment. Furthermore, sex differences in ERP topography and amplitude have been reported in children and adults ${ }^{(135,136)}$.

EEG/MEG can be used for testing the neurophysiological effects of pharmacological, rehabilitation or nutritional interventions immediately after an acute dose administration or after long-term programmes. EEG/MEG recordings are suitable for studying the group differences in between-group and within-group designs. Both techniques can be used in multicentric trials since the hardware of different brands can be easily calibrated and harmonised, although the availability of EEG is much wider than that of MEG, largely due to the much higher costs of MEG.

\section{Use of electroencephalography/magnetoencephalography in nutritional studies}

In the following, we highlight a selection of EEG and MEG papers to illustrate the resting-state, evoked potential (EP)/ evoked field and ERP/event-related field markers that capture the short-term (acute) and long-term (chronic) effects of nutrients on brain activity in healthy infants, children and adults. Specifically, with regard to acute effects, we focus on caffeine, and for the long-term effects of food interventions on brain function, we focus on studies that have investigated the effects of LC-PUFA as these nutrients have been repeatedly used to supplement milk formulas for infants and children during the developmental time course. Practically, no MEG studies on the effects of caffeine and LC-PUFA have been found. In the following paragraph, we summarise the main results and conclusions (Babiloni et al., unpublished results, 2012).

Caffeine has evident psychoactive effects at doses comparable to one to ten servings of tea or cola ${ }^{(137)}$ as assessed with the behavioural measures of cognitive function. A series of EEG and ERP studies have tested the effects of caffeine on brain activity during wakeful resting, mainly in adults and also in children and during ageing ${ }^{(138-144)}$ (see Lorist \& Tops $^{(145)}$ for a review). In these studies, resting-state EEG markers have been frequently used to study the psychoactive effects of caffeine, mostly at relatively high doses (200$500 \mathrm{mg}$ ) in adults. Generally, caffeine decreases $\alpha$ power, which indicates increased alertness or arousal ${ }^{(146)}$ consistent with the behavioural literature (see Ruxton ${ }^{(137)}$ for a review). Both behavioural and EEG studies struggle with the same fundamental questions such as how to correct for habitual caffeine use and body weight and to what extent caffeine effects can be attributed to the relief of withdrawal effects. Therefore, traditional background EEG measures may not add significant insights into the behavioural measures of caffeine effects, but it could be speculated that statistical functional coupling of resting-state EEG rhythms at electrode pairs as revealed by additional mathematical techniques, such as spectral coherence (linear), directed transfer function (linear) and synchronisation likelihood, might provide more informative markers about the caffeine effects ${ }^{(122)}$. These variables have been successfully used to disentangle abnormal changes of functional connectivity in the resting-state condition in elderly subjects suffering from preclinical or earlier stages of $\mathrm{AD}^{(128-132)}$ as well as after acute administration of nicotine, cocaine, marihuana, alcohol or medications ${ }^{(147-151)}$. The changes in functional connectivity measures in mild AD have been the target of a recent multi-country randomised controlled trial with a medical food. The studied product provides the nutritional precursors and cofactors for the formation of neuronal membranes, aiming to improve synapse formation and function in $\mathrm{AD}$; hence, the study included EEG measures as secondary outcomes as markers for synaptic connectivity ${ }^{(152)}$. Findings included significant amelioration in peak frequency and functional connectivity in the $\delta$ band over the 24-week intervention period in the experimental group compared with the control, suggesting preserved and even increased synaptic function resulting from the intervention ${ }^{(152)}$. In addition to resting-state EEG, several ERP studies have investigated the effects of caffeine on the brain using simple (e.g. rapid visual information processing and oddball) or more complex (e.g. switch task) attention tasks. ERP studies have added more detailed insights into what aspects of attention are improved by caffeine (generally processes following simple stimulus processing) and at which level of information processing (complex tasks seem to show more benefits).

With regard to the effects of long-term food interventions, LC-PUFA have been the subject of many studies, particularly those on infant development. Several studies using ERP and resting-state EEG measures have investigated diet-related effects of $n-3$ and $n-6$ fatty acids in mothers and infants, as well as in healthy adults ${ }^{(153-164)}$. In summary, diets with $n-3$ and $n-6$ fatty acids can influence resting-state EEG, not only in infants and children during development but also in adults, suggesting increased plasticity of neuronal membranes and synaptogenesis. The large majority of ERP studies have focused on EP, especially visual EP have been used as functional markers of the maturation of the visual system of infants fed with a LC-PUFA-supplemented formula or a control formula for 12 months ${ }^{(165,166)}$. In the same vein, auditory EP or brainstem auditory EP have similarly been used as functional markers of the auditory system ${ }^{(167,168)}$. Indeed, from a neurodevelopmental perspective, visual EP and brainstem auditory $\mathrm{EP}$ are the measures of choice for probing the maturation of the visual and auditory systems during development in infants and children before the acquisition of the verbal skills required for behavioural tests. Compared with the control group, preterm infants with low birth weights $(<1500 \mathrm{~g})$ receiving $n-3$ and $n-6$ supplementation for 9 weeks showed a significantly lower amplitude of ERP in response to frequently presented pictures, a possible reflection of a better short-term recognition memory of these frequent pictures ${ }^{(169)}$. In school-aged children and adults, ERP during oddball tasks (measuring sustaining attention to a continuous stream of stimuli and responding to pre-specified infrequent target stimuli) and Go-Nogo paradigms (assessing sustaining attention 
to a continuous stream of stimuli and responding to all stimuli except to predefined infrequent target stimuli) demonstrated some effects of $n-3$ and $n-6$ fatty acids on visual and auditory attention and motor processes. Sparse use of resting-state EEG markers can be explained by the large variability of these markers during development. Finally, the literature on the effects of $n-3$ and $n$ - 6 fatty acids on resting-state MEG and event-related fields is practically non-existent.

\section{Methodological limitations and recommendations of relevance to intervention studies}

In the previous section, we had highlighted a selection of EEG studies in healthy subjects on the effects of caffeine as an example of short-term psychostimulant effects (having acute effects on brain function) as well as LC-PUFA as examples of nutrients that have a long-term effect on brain structure and thus on function (chronic effects). Both resting-state EEG and EP/ERP markers have been successfully used for this purpose. For caffeine, the results are in line with the behavioural literature, confirming that caffeine improves attention. The majority of EEG studies on caffeine have used relatively basic attention tasks with a large perceptual component; the lack of use of more 'cognitive' attention paradigms such as the Posner attention task ${ }^{(170)}$ is striking in caffeine research, but it is in fact present in other nutritional research. There seems to be a disconnection between advances in behavioural measure of attention and the development of EEG/ERP tasks. The brain imaging area could benefit from the monitoring of developments in the behavioural area.

For $n-3$ and $n-6$ fatty acids, visual EP and brainstem auditory EP are even considered the gold standard for the assessment of the maturity of the nervous system ${ }^{(168,171)}$. In this age group, adapted and validated behavioural measures of development exist (e.g. the Bayley scales) and are the preferred measures of neurodevelopment, especially in premature infants.

Moreover, we think that resting-state EEG and EP/ERP markers could be greatly enhanced using advanced highresolution EEG techniques rather than simple computation of power density spectra or amplitude/latency of $\mathrm{EP} /$ ERP peaks at a few scalp electrodes. Another promising perspective is the development of EEG markers probing the functional coupling of EEG rhythms as revealed by spectral coherence, directed transfer function and synchronisation likelihood $^{(128-132,147-151)}$. Finally, it is expected that MEG techniques could greatly contribute to an accurate modelling of functional topography of the cortical sources of the recorded MEG data in the near future, thanks to the increasing availability of MEG systems worldwide.

\section{Near-IR spectroscopy: measuring cerebral blood flow and haemodynamic responses}

Near-IR spectroscopy techniques and near-IR spectroscopy-derived measures

NIRS involves the introduction of two or more wavelengths of near-IR laser or light-emitting diode light through the intact skull with subsequent measurement of light absorption following diffusion through the upper layers of the cortex by optodes positioned at a set distance from the emitter. The differential intrinsic oxygenated and deoxygenated $\mathrm{Hb}$ in the surface of the cortex give measures of oxy-Hb and deoxy-Hb and their sum (total $\mathrm{Hb}$ ), which represent proxy measures of blood volume or blood flow in the interrogated neuronal tissue; therefore, NIRS serves as a marker for neural activation. Activity and blood flow in the brain are inextricably linked by the neurovascular coupling of local neuronal activity to blood flow, whereby a number of signalling molecules and physiological mechanisms serve to increase the delivery of blood-borne metabolic substrates to active tissues ${ }^{(172,173)}$. When assessed by NIRS, the haemodynamic response to local neural activity will be seen as an increase in $\mathrm{CBF}$, which in turn will be evident as an increase in the concentrations of both oxy- $\mathrm{Hb}$ and total $\mathrm{Hb}$ and a corresponding comparative decrease in deoxy-Hb level ${ }^{(174)}$. NIRS outcomes can therefore be taken to infer local neural activation or, alternatively, can be interpreted more directly as simple changes in blood flow/volume in the underlying cortical tissue. The latter is particularly pertinent as both CBF and the magnitude of the haemodynamic response to neural activity decrease with normal ageing and in neurological disease $^{(173)}$. A large and expanding literature has described the use of NIRS as a tool for multiple-channel imaging of the haemodynamic correlates of neural activation across the lifespan in healthy cohorts. As an example, in groups of neonates, children and infants, NIRS has been used to investigate neuronal activation across diverse cortical brain regions as a consequence of auditory, visual and olfactory stimuli ${ }^{(175)}$. In adults, NIRS has been widely adopted to investigate the location and extent of cortical responses during diverse motor tasks ${ }^{(176)}$, haemodynamic responses to sensory stimuli $^{(177)}$ and during cognitive tasks ${ }^{(178)}$. Across these areas, NIRS has shown itself to be sensitive enough to reliably illuminate age-related changes in CBF. For instance, it has been used to demonstrate an inverse correlation between age and haemodynamic response in non-elderly adults during verbal fluency tasks ${ }^{(179)}$ and hypoxia ${ }^{(180)}$. Similarly, it has been utilised to show reduced haemodynamic responses in older adults in comparison with younger adults during verbal fluency $^{(181)}$ and executive function ${ }^{(182)}$ tasks, as well as during postural changes ${ }^{(183)}$ and simulated driving ${ }^{(184)}$.

NIRS systems vary in complexity from single or dual channels to 'whole-head' arrays of several dozen channels and fall into several categories depending on the measurement technique that they employ: 'continuous-wave' systems emit light continuously at constant amplitudes, and only the amplitude decay is measured; 'time-domain' systems emit short bursts of photons, with the temporal distribution providing information about tissue absorption and scattering; 'frequency-domain' systems emit amplitude-modulated light and record amplitude decay and phase shift ${ }^{(185)}$. Within these categories, there is a plethora of variants, and a number of new techniques are in the process of development ${ }^{(186,187)}$. Each of these systems has its own advantages and disadvantages. As an example, the most widely used system for brain imaging 
and clinical applications to date has been the continuouswave system, which provides continuous, extended recording with a high temporal resolution, is easy to apply, allows movement during measurement and is comparatively cheap and portable and of very low running costs. However, its major disadvantages include its limited depth of penetration and its use of an arbitrary value for the (unknown) path length of light in its calculation of $\mathrm{Hb}$ concentrations (using a modified Beer-Lambert formula), therefore only providing 'change in concentration' measurements rather than quantifying the absolute levels of oxy-Hb and deoxy- $\mathrm{Hb}^{(188)}$. It is therefore only suited to measuring the haemodynamic responses to task-related neural activation or the acute and chronic effects of an intervention in terms of how it modulates the haemodynamic response to task performance. It is also ideal for continuous measurement of the very short-term (maximum of several hours) effects of acute interventions. Recent 'quantitative' systems resolve this measurement issue by collecting light at several increasing distances from the light source, allowing the exact calculation of the path length and thereby the absolute quantity of $\mathrm{Hb}$ in the underlying tissue. These systems, which have advantages in terms of cost and practical considerations similar to those of earlier continuous-wave systems, will be ideally suited to studies of either the acute or chronic effects of an intervention in terms of both absolute quantities and haemodynamic responses. While NIRS parameters have been shown to correspond strongly with the fMRI BOLD signal ${ }^{(174,189,190)}$, there are advantages and disadvantages associated with the two imaging techniques. NIRS has a high temporal resolution (up to $250 \mathrm{~Hz}$ ) and is certainly comparatively cheap, easy to use and suitable for measuring during most tasks for long periods. It also generates data that can be analysed using standard statistical methods. However, it does not have the comparatively high spatial resolution of fMRI, and it only provides information about blood flow parameters in the upper layers of the cortex.

\section{Eligibility for a near-IR spectroscopy examination}

NIRS originated as a clinical tool ${ }^{(191)}$ and continues to be widely used across the lifespan in this context. For example, its uses include the monitoring of cerebral haemodynamics and oxygenation across critical illnesses in neonates, infants and children ${ }^{(192)}$. It is also used during anaesthesia ${ }^{(193)}$ and in clinical research into neurological conditions, including perinatal asphyxia, epilepsy and brain development ${ }^{(194,195)}$. Similar applications in adults include use during surgery, resuscitation and cardiac failure ${ }^{(196,197)}$ and the identification and rehabilitation of brain injury ${ }^{(176,196,198)}$. NIRS has also been used to demonstrate reduced $\mathrm{CBF}$ or haemodynamic responses during cognitive tasks in groups suffering from a number of neurological or neurodevelopmental conditions, including age-associated cognitive impairment and dementia $^{(199)}$, schizophrenia ${ }^{(200)}$ and attention-deficit hyperactivity disorder (ADHD) ${ }^{(201)}$

NIRS has also proven itself to be a sensitive research technique for assessing the modulation of CBF across the lifespan, from neonates ${ }^{(175)}$ to older adults ${ }^{(177,181)}$, in diseased and healthy subjects, and it reliably illuminates age-related changes in CBF elicited by sensory stimuli or cognitive task performance ${ }^{(179,180,182-184)}$. In general, NIRS research has been conducted in mixed-sex groups.

NIRS has rarely been employed in pharmacological trials in adult samples. Beyond a number of drug trials related to its clinical use in anaesthesia ${ }^{(202)}$, it has been used to demonstrate a reduced haemodynamic response in the prefrontal cortex during cognitive tasks following methylphenidate use in children with $\mathrm{ADHD}^{(203)}$ and following sedating antihistamine use in children ${ }^{(204)}$. Similarly, it has been used to show decreased frontal lobe oxygenation following the administration of sumatriptan ${ }^{(205)}$ and phenylephrine ${ }^{(206)}$ and increased oxygenation following the use of the vasodilator vinpocetine ${ }^{(207)}$

\section{Use of near-IR spectroscopy in nutritional studies}

NIRS provides an accessible measure of the CBF effects of the many nutritional factors and dietary components that may modulate blood flow either over the short term or indeed across the lifespan. However, to date, only a handful of studies have utilised NIRS to assess the cerebral haemodynamic effects of nutrients and food components. The only such study in infants ${ }^{(208)}$ has demonstrated reduced CBF (tissue oxygenation index representing the ratio of oxy-Hb:deoxy$\mathrm{Hb}$ ) in the temporo-parietal region following the administration of a single dose of caffeine, administered primarily as a respiratory stimulant, to forty preterm infants. A number of double-blind, placebo-controlled trials have also assessed the effects of nutritional interventions on $\mathrm{CBF} /$ neural activity in adults as measured by one or two channels positioned over the frontal cortex during tasks that activate this brain region. For instance, Kennedy \& Haskell ${ }^{(209)}$ confirmed the vasoconstricting properties of caffeine in healthy adults (total $\mathrm{Hb}, n$ 20, cross-over design). NIRS has also been used to demonstrate a dose-related increase in CBF (total $\mathrm{Hb}$ ) and deoxy-Hb level in the frontal cortex during task performance following the administration of single doses of the polyphenol resveratrol ( $n$ 22, cross-over design ${ }^{(210)}$ ) and a decrease in CBF (total $\mathrm{Hb}$ ) during tasks following the administration of two single doses of the tea polyphenol epigallocatechin gallate ( $n$ 27, cross-over design ${ }^{(211)}$ ). The above-mentioned findings mirror those from studies using a variety of other imaging techniques in the case of caffeine and animal models in the case of the polyphenols. Several controlled trials have also investigated longer intervention periods. For instance, Watanabe et $a l .^{(212)}$ demonstrated modulated haemodynamic responses in terms of decreased oxy-Hb and increased deoxy-Hb levels during cognitive tasks following $5 \mathrm{~d}$ administration of creatine to a small sample of adults ( $n$ 24, parallel groups). In two investigations of the effects of $n-3$ fatty acids, Jackson et al. ${ }^{(213)}$ demonstrated that 12-week administration of DHA-rich fish oil, but not of EPA-rich fish oil, increased the frontal cortex haemodynamic response in terms of total $\mathrm{Hb}$ and oxy-Hb during 'frontal' task performance in a small sample of twenty-two healthy young adults. Jackson et $a{ }^{(214)}$ subsequently confirmed the dose-dependent nature 
of the effects of the DHA-rich fish oil in a larger sample of sixty-five adults.

\section{Methodological limitations and recommendations of relevance to intervention studies}

Taken together, these studies suggest that NIRS is adequately sensitive to detect the CBF effects of nutrients and food components. However, although NIRS can be used to reliably demonstrate $\mathrm{CBF}$ and haemodynamic responses to cognitive task performance, there is little evidence to date of a direct relationship between changes in $\mathrm{CBF}$ inculcated by nutritional interventions and corresponding benefits in terms of the speed or accuracy of cognitive performance per se. This collection of studies also highlights the constraints associated with much of the NIRS research to date. The first of these is that the studies have generally only employed either one or two channels, typically covering the prefrontal cortex, rather than the distributed network of channels across the frontal cortex or head that the technique can accommodate. The second is that the most commonly used continuous-wave NIRS systems can only measure changes in concentrations during the period of recording, rather than providing data reflecting the absolute levels of oxy/deoxy-Hb. This makes them well suited to assessing the acute effects of an intervention, such as caffeine or resveratrol (with uninterrupted recording from pre-dose), or suitable for assessing the effects of a chronic treatment in terms of the magnitude of the increase from a resting baseline in blood flow/volume during task performance (i.e. the haemodynamic response). The latter measure is undoubtedly of interest, but it alone is unlikely to constitute the main outcome of any study assessing the effects of long-term administration of nutrients or indeed the cross-sectional/prospective relationships between nutrients and brain function.

It is also necessary to note that the more recently introduced quantitative NIRS systems combine the ease and mobility of measurement, portability and low costs of the continuouswave systems and generate data representing the absolute quantity of oxy/deoxy-Hb in the interrogated cortical tissue. This step change in measurement technology, in concert with increased sophistication in terms of the number and location of channels across the head, should make NIRS a particularly useful and cost-effective imaging technique in nutrition-related studies in the future, especially as NIRS can be combined successfully with most other imaging techniques and can be used across ages and in concert with complex cognitive or physical movement paradigms.

\section{Positron emission tomography imaging: anatomical, metabolic and functional assessments for nutritional research}

\section{Positron emission tomography techniques and positron emission tomography-derived measures}

Functional neuroimaging procedures, such as PET and SPECT, measure the metabolic and physiological processes of the
CNS. When combined with structural imaging techniques, PET and SPECT determine the exact anatomical location and the physiological and metabolic effects of a nutrient on the brain.

To perform PET, a radiotracer is produced by attaching a radioactive atom to a molecule or a compound of biological interest. Directly following its synthesis, the radiotracer begins to decay and release positively charged positrons from the nucleus. A positron has the kinetic energy to travel a few millimetres within the tissue. When almost at rest, the positron interacts with an unbound electron. Since the two particles have an opposite charge, they annihilate each other, resulting in two $\gamma$-ray photons of $511 \mathrm{keV}$ energy being emitted at $180^{\circ}$ from each other ${ }^{(215)}$. In a PET scanner, rings of radiation detectors that surround an individual's head for brain studies or another body part of interest detect the $\gamma$-ray photons. Pairs of these radiation detectors are oriented to face each other at $180^{\circ}$ and are connected by an electronic coincidence circuit that detects the photons emitted during the annihilation event when the positron meets an electron and that converts light energy into electrical energy to measure the number of photon pairs originating from all angles in the brain. Through a computer reconstruction algorithm, it is possible to determine both the amount and location of the $\gamma$-ray photons on a regional basis throughout the brain and to produce a threedimensional image or picture. Due to the distance of few millimetres travelled by the positron before the annihilation event occurs, PET has an intrinsic limitation in spatial resolution. The number of positron/electron collisions at each site in the brain is proportional to the amount of the radiotracer present at the site. Hence, the relative amount of relevant activity being evaluated with respect to activity at other brain sites can be determined.

PET enables in vivo visualisation by tracking radioactive compounds (i.e. radiotracers) that are of potential biological importance in the body ${ }^{(216)}$. PET tracers typically are identical or similar in structure (i.e. they are analogues) to naturally occurring molecules that act in particular brain areas. Depending on the radiotracer, PET can provide measures of regional cerebral glucose metabolism, blood flow and neurotransmitter metabolism in a variety of physiological conditions and in neurological or psychiatric disorders ${ }^{(217)}$

The best-known example of a PET tracer is $\left[{ }^{18} \mathrm{~F}\right]$ fluoro2-deoxy-D-glucose (FDG). FDG is an analogue of glucose that is labelled with ${ }^{18} \mathrm{~F}$ and has a radioactive half-life of $110 \mathrm{~min}$. Glucose serves as the source of energy in active brain cells. Thus, regional cerebral metabolic rates for glucose, as determined using PET with this tracer, represent a reliable index of functional synaptic activity in the human $\mathrm{CNS}^{(218,219)}$. After an intravenous bolus injection, FDG reaches the brain via blood flow and, similar to glucose, can be transported across the cerebral capillary bed into the neurons by a monosaccharide transport system. Once inside brain cells, FDG is phosphorylated to FDG-6-phosphate, but unlike glucose-6-P, FDG-6-phosphate is not further metabolised by glycolytic pathway enzymes and remains essentially trapped inside brain cells during the duration of the scan ${ }^{(219)}$. Therefore, the quantity of FDG-6-phosphate that has accumulated 
in a brain region during $45 \mathrm{~min}$ of uptake after FDG intravenous injection is measured by PET, and it reflects the rate of phosphorylation of glucose to glucose-6-P and the plasma integral of FDG to which the brain is exposed ${ }^{(220)}$. Using an operational equation $^{(219)}$, regional cerebral metabolic rates for glucose are calculated from the quantity of FDG-6-phosphate within the brain, the ratio of the integrated plasma activity of FDG to non-radiolabelled plasma glucose concentration during $45 \mathrm{~min}$ of uptake and a 'lumped constant' that corrects for the use of FDG in place of unlabelled glucose.

By binding the radioactive compound to specific proteins (e.g. transporters, receptors or enzymes), PET can be used to evaluate the state of neurotransmitter systems, revealing, for instance, the activity of enzymes involved in the synthesis and metabolism of a given neurotransmitter, such as serotonin or dopamine, or the number of receptors present ${ }^{(221)}$. PET may also reveal the variety of physiological processes mediated by the receptor system. In general, the dose of the radiotracer for a routine PET scan is approximately 1000 times lower than that required to produce a pharmacological effect $^{(222)}$. Hence, the radiotracer does not interfere with the ongoing conditions under study.

In addition to fluorine, other radioactive atoms used in PET studies are carbon $\left({ }^{11} \mathrm{C}\right)$ and oxygen $\left({ }^{15} \mathrm{O}\right)$. As a freely diffusible tracer, $\mathrm{H}_{2}{ }^{15} \mathrm{O}$ quickly equilibrates between brain and blood and provides an excellent indicator of regional $\mathrm{CBF}$ (rCBF), another reliable index of neuronal activity. Immediately following an intravenous injection of a bolus of $\mathrm{H}_{2}{ }^{15} \mathrm{O}$, a PET scan that can last from 1 to $4 \mathrm{~min}$ is acquired to measure local radioactivity in the distinct cortical and subcortical brain regions. Radioactivity can be concurrently measured in the blood by sampling from an indwelling arterial line that is connected to an automatic counter. Using a mathematical model, it is possible to determine absolute rCBF values in terms of $\mathrm{ml} / 100 \mathrm{~g}$ tissue per min.

Since the radioactivity of ${ }^{15} \mathrm{O}$ has a rapid decay (half-life $2.05 \mathrm{~min}$ ), multiple scans can be performed sequentially in the same individual, ranging from 6 to $12 \mathrm{~min}$ apart. This makes it possible to evaluate rCBF repeatedly in a single PET session, while the subject is in the 'resting state' with no sensory stimulation or engaged in performing a variety of tasks. By subtracting a baseline rCBF scan from a task rCBF scan, regions where activity is specifically altered during the task can be identified. In such rCBF studies, arterial blood $\mathrm{P}_{\mathrm{a}} \mathrm{CO}_{2}$ is monitored so that global CBF can be corrected when differences in $\mathrm{P}_{\mathrm{a}} \mathrm{CO}_{2}$ occur. Over the last few years, fMRI has largely been replaced with PET to study changes in regional brain activity by measuring blood flow-related phenomena, because of the greater space and time resolution and the lack of any radioactive exposure.

Due to its methodological features and radionuclide specificities, PET is adapted to measure neural activations during specific tasks and the acute and chronic effects of an intervention in terms of how it modulates both the neural response to task performance and the metabolism of different neurotransmitters.

\section{Eligibility for an examination with positron emission tomography}

PET scanning is useful for understanding adult brain function, but the use of short-life radioactive compounds poses a strict limitation to the number of PET scan examinations that an individual may undergo within a given period of time. It is also considered impractical to use this approach in healthy children and adolescents for radiation safety reasons. Hence, in the young, the technology is only used for diagnosis in which the risk is outweighed by the benefit.

\section{Use of positron emission tomography in nutritional studies}

The number of nutritional studies using PET techniques is limited. This is not surprising due to the high cost of the technology, its limited availability and the short half-life of radiotracers. Due to radiation, most of the studies available either have examined the effect of nutrition in the adult brain or are clinical studies in children. Past studies have leveraged PET analysis as a tool for identifying the effects of various stimuli on neurotransmission, blood flow and glucose uptake. The technique can map potential CNS mechanisms mediating whole-body energy balance by regulating energy intake and expenditure in healthy men and women and in those deviating from 'healthy'. These data show that interindividual and sex differences in behaviour may have neurobiological correlates. In several studies ${ }^{(172,223-225)}$, PET has been used to measure rCBF, a marker of neuronal-synaptic activity, to investigate the functional neuroanatomy of sex differences and differences between lean and obese individuals in hunger and satiation. Hunger was associated with significantly increased neuronal activity in the vicinity of the hypothalamus and thalamus, which are areas described previously as important in the regulation of feeding behaviour in animals. Hunger was also associated with increased activation in the vicinity of the limbic and paralimbic areas, regions involved in affect and motivation. In contrast, satiation was associated with increased activity in prefrontal cortical areas implicated in aspects of response inhibition. The changes in activity in the putamen and cerebellum associated with hunger suggested the involvement of brain regions not previously associated with the regulation of food intake. PET has also demonstrated extensive similarities, as well as some differences, between the sexes. In response to hunger, men tended to have greater activity in the frontotemporal and paralimbic systems than did women ${ }^{(172)}$. In response to satiation, women tended to have greater activity in the occipital and parietal sensory association areas and in the dorsolateral prefrontal cortex than did men, and men tended to have greater activation in the prefrontal cortex than did women ${ }^{(172)}$. Sexspecific responses indicate possible neurobiologically based differences in men and women in cognitive and emotional processing of hunger and satiation.

Only a few neuroimaging studies have explored the effects of modifications in nutritional lifestyle on the brain functional and anatomical correlates. Small et al. ${ }^{(226)}$ have recently used PET with cognitive and memory tests to assess brain metabolic 
and functional correlates of a $14 \mathrm{~d}$ healthy longevity programme. Volunteers in the intervention programme were requested to follow a diet plan and to practise relaxation exercises, cardiovascular conditioning and mental exercise (brain teasers and verbal memory training). The diet plan used in this study included five daily meals and emphasised antioxidant-rich fruits and vegetables, $n-3$ fats and low-glycaemic index carbohydrates. FDG-PET scans and cognitive tests were performed before and after the intervention, and the results were compared with those obtained from a group of control subjects, who continued with their usual lifestyle routine. Individuals in the intervention group showed improved performance in a word fluency test, while the PET scans identified a $5 \%$ decrease in cerebral glucose metabolism in the dorsolateral prefrontal cortex. The authors interpreted these results as signs of increased cognitive efficiency consequent to the temporary modification in lifestyle.

Another neuroimaging study has investigated brain functional correlates of dietary restraints and successful dieting. Del Parigi et al. ${ }^{(227)}$ used an $\mathrm{H}_{2}^{15} \mathrm{O}$ radiotracer to evaluate brain response to the sensory experience of food consumption comparing a group of successful female dieters (i.e. successful weight loss maintainers) with a group of non-dieters. The authors observed that after meal consumption, successful dieters showed greater brain activation in the dorsal prefrontal cortex, dorsal striatum and anterior cerebellar lobes when compared with non-dieters. Vice versa, the orbitofrontal cortex showed greater activation in non-dieters when compared with successful dieters. In addition, dietary restraint, assessed using the Three-Factor Eating Questionnaire ${ }^{(228)}$, correlated positively with the response in the dorsal prefrontal cortex and negatively with the response in the orbitofrontal cortex. Finally, a negative correlation was observed between the response in the dorsal prefrontal cortex and that in the orbitofrontal cortex. Given these results and the role recognised for these two brain regions in cognitive control of behaviour ${ }^{(229)}$ and codification of the reward value of stimuli $^{(230)}$, respectively, the authors hypothesised that an inhibitory loop may exist between these two areas in successful dieters. In other words, cognitive control of food intake may be achieved, thanks to a modulatory signal generated in the dorsal prefrontal cortex, and directed to regions involved in food reward such as the orbitofrontal cortex ${ }^{(231)}$.

Nugent et al. ${ }^{(232)}$ questioned whether cerebral glucose hypometabolism mediates changes in cognitive function during healthy ageing. Based on epidemiological studies suggesting that dietary $n$-3 PUFA ingestion from weekly consumption of a fatty fishmeal protects cognitive function in the elderly, the study sought to determine whether fish oil supplementation rich in $n$-3 PUFA increases cerebral glucose metabolism. PET analyses utilising $\left[{ }^{18} \mathrm{~F}\right] \mathrm{FDG}$ were used to assess cerebral glucose metabolism in young and elderly adults. Healthy young and elderly subjects received fish oil capsules daily for 3 weeks (DHA and EPA). Both brain

${ }^{18}$ FDG-PET analysis and an oral glucose tolerance test were performed at baseline and at the end of the treatment. The results failed to differentiate age or $n$-3 PUFA supplementation effects on glucose metabolism in any of the brain regions evaluated.

Because of the limited number of existing reports, we describe types of studies that could usefully employ PET analyses to examine the effects of a nutritional intervention on brain function. Published study protocols for children with Tourette's syndrome or ADHD illustrate how PET imaging can be used with regard to a nutritional intervention to modulate brain function. Tourette's syndrome is a neurological condition presenting with chronic motor and phonic tics during childhood that persists into maturity. Current standard treatment achieves partial control of the condition and provokes significant adverse effects. In 2002, Grimaldi ${ }^{(233)}$ hypothesised that $\mathrm{Mg}$ and vitamin $\mathrm{B}_{6}$ deficiencies may be the precipitating factors in the neurochemical pathways mediating Tourette's syndrome symptomatology. To confirm this hypothesis, Garcia-Lopez et al. ${ }^{(234)}$ reported on a study protocol designed to assess the effects of a combination of $\mathrm{Mg}$ and vitamin $\mathrm{B}_{6}$ supplementation $v$. placebo on metabolic changes measured by PET in the brain in conjunction with a reduction in motor and phonic tics and incapacity, as well as in quality of life, in children aged 7-14 years with exacerbated Tourette's syndrome ${ }^{(234)}$. PET imaging will be performed before and after the treatment, in order to ascertain treatment effects on dopaminergic activity within the basal nuclei and in the prefrontal cortex. Thus, PET imaging can be employed as a tool to evaluate alternative hypotheses of nutritional effects on brain function under clinical conditions.

PET has been used to examine brain metabolism in children with $\mathrm{ADHD}^{(235)}$. ADHD is a very common and heterogeneous disorder with an onset in children. The key features include persistent symptoms of inattention, hyperactivity and impulsive behaviour. Approximately $15 \%$ of patients appear refractory to the standard of care with psychostimulants. Dysfunction of the dopamine transporter is known to be involved in its pathogenesis. Because the dopamine transporter is regulated by $\mathrm{Zn}$, Zn deficiency may contribute to the dysfunction of the dopamine receptor and its supplementation may be required for treatment and/or as an adjunct to the psychostimulants $^{(236)}$. Lepping \& Huber ${ }^{(236)}$ have proposed to test their hypothesis by recruiting Zn-deficient ADHD patients who will undergo PET with the $\left[{ }^{11} \mathrm{C}\right]$ raclopride displacement method to investigate whether $\mathrm{Zn}$ increases extracellular dopamine levels

Later in life, PET could be used to study the effects on brain functioning and metabolism of nutrients thought to be efficacious in maintaining, preventing or reversing cognitive decline among the elderly. The ability to avert, or at least reduce, the rate of cognitive decline in the elderly would be enormously beneficial to public health. The most common form of cognitive decline in the elderly is AD. The global presence of this condition is expected to increase considerably over the next few decades, resulting in overwhelming demands for socioeconomic and medical resources ${ }^{(237)}$. Although various forms of therapeutic interventions have been used in $\mathrm{AD}$, no treatment has proven capable of curing or remitting the progression of the disease. The clinical demonstration of potential treatments is arduous since it necessitates large 
study populations and long-term follow-up. PET analyses may offer cost-benefit options to evaluate alternative therapies. For example, emerging science has indicated that regional cerebral glucose hypometabolism as measured by ${ }^{18}$ FDG-PET reflects cognitive decline associated with ageing ${ }^{(238,239)}$ and dementia, such as $\mathrm{AD}^{(240)}$. Hence, treatments that attempt to reverse or retard the course of illness by enhancing glucose utilisation of neurons, which can be assessed by PET with the FDG radiotracer, may prove efficacious.

In the future, PET analyses may represent an important tool in evaluating the effects of nutrient deficiencies and supplementation on neurotransmission, glucose uptake and blood flow underlying the pathological conditions.

\section{Methodological limitations and recommendations of relevance to intervention studies}

Developing models for interpreting findings of positron emission tomography analyses. Most of the radiotracers used for PET have relatively short half-lives. For example, the half-lives for radiotracers of carbon and oxygen are 20 and $2 \mathrm{~min}$, respectively $^{(222)}$. As a result, PET radiotracers must typically be produced at the same site as the PET scan activities in order to avoid losing most of the radioactivity. Radiotracers are produced by cyclotrons, machines that are extremely expensive and bulky, and require radioactive shielding. Hence, PET scans are also limited in availability. In contrast, recent developments in radiotracers have provided products with longer half-lives that permit the possibility of PET scan usage in facilities without cyclotrons.

Data obtained with PET are typically subjected to a set of processing steps to yield useful information. PET follows the progress of the tracer by measuring the amounts of radioactivity in different areas of the brain as well as the tracer concentrations in the blood. These dual datasets are subjected to mathematical or statistical modelling methods for interpretation. For example, mathematical representations of physiological processes such as the metabolism of neurotransmitters are used to develop mathematical equations describing the tissue response curve expected in the measurements. The tissue response curve plots the radioactivity of specific parts of the brain before, during and after the radiotracer injections. By identifying those variables in the model that give the best agreement between the expected and measured values, the physiological processes can be quantified.

Correcting for partial volume errors. Compared with structural imaging (e.g. MRI), PET images are blurred due to the limited resolution of the scanners (i.e. inability to distinguish between closely spaced regions of small dimensions). This may result in two consequences: (1) an apparent loss or spill-out of radioactivity signals from a small region of interest into the adjacent tissues due to the size of the small brain region compared with the spatial resolution of the scanner, or (2) spill-in of radioactive signals into the regions of interest from adjacent brain areas with different radioactivity tracer concentrations. The latter are known as partial volume errors. Corrections for partial volume errors involve computer simulations to mimic the effect of limited spatial resolution in order to characterise the partial volume effects for each brain region. This information allows the application of correction factors to obtain more accurate estimates of the actual regional activity.

PET scans are increasingly read alongside a computed tomography or MRI scan. The combination gives anatomical and metabolic information (what the structure is and what it is doing biochemically). However, the MRI-PET procedure is time consuming, technically demanding and expensive. Hence, it is not widely available and is used in limited research settings.

\section{Single-photon emission computerised tomography imaging: anatomical, metabolic and functional assessments for nutritional research}

\section{Single-photon emission computerised tomography techniques and single-photon emission computerised tomography-derived measures}

Similarly to PET, SPECT is a tomographic imaging methodology that employs $\gamma$-ray-emitting radioisotopes that are attached to ligands of interest. In SPECT imaging, however, isotopes that emit a single $\gamma$-ray photon are used. This fundamental difference from the radiotracers used in PET, which emit two photons, accounts for the principal differences in instrumentation and capabilities to measure functional brain activity. SPECT visualises the physiological or metabolic functioning of living human subjects, and it is mainly used to measure blood perfusion and neurotransmitter distribution in a variety of physiological conditions and in neuropsychiatric disorders.

The principal radiotracers currently used in SPECT assess neural activity by measuring $\mathrm{rCBF}$, although radiotracers to assess the characteristics of several neuroreceptor systems, including the cholinergic, dopaminergic and serotoninergic systems, have also been developed ${ }^{(241,242)}$. The most commonly used radiotracers to measure $\mathrm{rCBF}$ in SPECT include $\left.{ }^{99 \mathrm{~m}} \mathrm{Tc}\right]$ hexamethylpropyleneamine and $\left[{ }^{99 \mathrm{~m}}\right.$ Tc]ethyl cysteinate dimer. The radiotracer $\left[{ }^{123} \mathrm{I}\right]$ isopropyl iodoamphetamine has also been widely used to measure rCBF with SPECT. Although employed initially in non-tomographic imaging, the use of Xe-133 has continued with SPECT. With a relatively fast clearance, this particular radiotracer allows for multiple scans in the same SPECT session, but offers a relatively low spatial resolution $^{(243)}$. With the implementation of multiple-head SPECT cameras, sensitivity and spatial resolution have significantly improved. However, SPECT continues to have a lower spatial resolution than PET and has a greater difficulty in identifying deep brain structures.

In general, compared with positron-emitting tracers in PET, the radioisotopes in SPECT emit lower-energy photons (i.e. $80-159 \mathrm{keV})$. These are more susceptible to attenuation as the photons travel through tissue, especially in deeper brain structures. Thus, brain structures similar to the basal ganglia, which are farther from the detector surface, have a poorer resolution than cortical brain regions. This, in combination with the complexities in modelling tracer behaviour, makes full 
regional quantification of absolute rCBF difficult in SPECT. In practice, which is also often the case with PET, regional tissue counts in the cortex are typically referenced to global tissue counts or relatively preserved brain regions (e.g. cerebellum) to provide a semi-quantitative measure of cerebral perfusion.

As with PET, SPECT imaging of the brain involves two essential steps: (1) the administration of a radiotracer and (2) the use of a tomographic scanner to measure the regional distribution of the radiotracer in the brain. In SPECT, as in PET, scintillation crystals are used to detect the radioactivity emitted from the tracers. Since the emitted photons travel in all directions, SPECT depends on the use of collimators to determine the point of origin of the emitted photons and to localise the regional brain activity. These collimators are in the form of lead septa that are positioned in front of the scintillation crystal detectors. The apertures created between the septa serve to limit the exposure of the crystals to $\gamma$-ray photons that are arriving at a nearly perpendicular angle to the crystal surface. In PET, such septa are employed for two-dimensional image acquisition, but can be retracted in the new threedimensional image scanners.

Furthermore, the radioactive half-lives of $6 \mathrm{~h}$ for ${ }^{99 \mathrm{~m}} \mathrm{Tc}$ and $13 \mathrm{~h}$ for ${ }^{123} \mathrm{I}$, as well as the relatively slow washout of the high-resolution tracers, such as $\left[{ }^{99 \mathrm{~m}} \mathrm{Tc}\right]$ hexamethylpropyleneamine and $\left[{ }^{123} \mathrm{I}\right]$ isopropyl iodoamphetamine, significantly limit the ability to perform multiple scans to assess rCBF under different test conditions during the same scanning session.

Importantly, the greater ease of production and the potential for longer storage of these radiotracers, compared with the positron-emitting radiotracers used in PET, provide the advantage of eliminating the need for an on-site cyclotron. Despite the technical limitations of SPECT relative to PET, the wide availability and lower cost, combined with the ability to detect regional reductions in cortical perfusion with a spatial resolution that can approach that of PET, have made its use more popular in clinical assessments of neurodegenerative diseases in recent years. For detailed reviews of the procedures and technical considerations for SPECT, see the works of Devous et al. ${ }^{(244)}$, Juni et $a l^{(245)}$, Masdeu et al. ${ }^{(246)}$ and Van Heertum \& Tikofsky ${ }^{(247)}$.

\section{Eligibility for a single-photon emission computerised tomography examination}

SPECT scanning is mostly used for clinical purposes only, mainly in adult patients. It is considered impractical to use this approach in healthy children and adolescents primarily for reasons of radiation safety.

\section{Use of single-photon emission computerised tomography in nutritional studies}

SPECT shares clinical and research applications, limitations and methodological aspects with PET. Indeed, SPECT scanning has been mainly exploited for the possibility of assessing cerebral perfusion changes related to nutritional abnormalities. For instance, $\left[{ }^{99 \mathrm{~m}}\right.$ Tc]ethyl cysteinate dimer brain SPECT studies have revealed significant decreases in frontal perfusion in a group of patients with coeliac disease, similarly to what has been described previously in other autoimmune diseases but improvable by a gluten-free diet ${ }^{(248)}$. Similarly to what has been described previously, SPECT has also been used for evaluating changes in neurotransmitter metabolism in patients with eating disorders or obesity ${ }^{(249,250)}$ or to determine the effects of creatine nutritional supplementation in Parkinson's disease ${ }^{(251)}$ or vitamin $\mathrm{B}_{12}$ deficiency ${ }^{(251,252)}$ on brain functioning.

\section{Methodological limitations and recommendations of relevance to intervention studies}

The limitations and consideration relative to the methodological, experimental and data processing aspects that have been highlighted for PET are also valid for SPECT. As for PET protocols, but often with a lower spatial resolution and an ill-defined quantification of the activity distribution, SPECT use faces the issues of specificity and the intrinsic properties of radiotracers, the limited availability of scanners and the elaborate processing of images.

\section{General considerations}

The present review describes existing brain imaging technologies and how these have the potential to assess the effects of a nutritional intervention in human subjects. From early development to ageing, brain imaging can detect structural, functional and metabolic changes in human subjects. In addition, modifications due to altered nutrition or to additional nutritional supplementation have recently been evaluated with some of these techniques. There are two things that seem clear: first, the use of brain imaging in nutritional studies is not widespread; second, brain imaging techniques offer the promise of providing important and useful information about the effects that nutrition has on brain metabolism, structure and function. The literature reviewed here suggests that, on the whole, the brain imaging markers described can reliably reflect neurostructural, neurophysiological, neurochemical and functional cerebral changes occurring during the lifespan and potentially after nutritional interventions. Furthermore, these markers may increase our understanding of changes in brain and cognitive function associated with nutritional interventions $^{(66,67,69,76,84,94,137,145,209,211-213,231,232,248,251,252)}$. Significant effects of a short-term intervention with foods and nutrients have been demonstrated using MRI, EEG, NIRS and PET in adults, including sex effects, and special populations such as athletes ${ }^{(156,172,223-226)}$. Moreover, significant effects of a long-term intervention (i.e. months) with foods and nutrients have been demonstrated by these techniques in infants and children, as well as in elderly subjects ${ }^{(3,12,153-166)}$. Due to the relative infancy of most of these technologies, for the vast majority of imaging measures, little information is available regarding their correlation with functional endpoints in healthy subjects. Therefore, in the general healthy population, the use of imaging markers as surrogates for functional endpoints is not well developed and for most markers it is inappropriate. The key added value of these measures for 
human nutritional intervention studies is their opportunity to provide unique in vivo information on the working mechanism of the intervention.

Although imaging techniques are capable of providing new and reliable information on brain structure and function, it must be remembered that they have their limitations and caution must be exercised, particularly when interpreting negative results. Finding no imaging changes may indicate that the intervention has had no effect on brain structure and/or function. An equally valid conclusion, however, may be that the imaging methodology is not sensitive enough to reveal changes that have in fact occurred. In addition, while behavioural measures of cognitive function in longitudinal studies are often subject to, for instance, relatively large practice effects that may complicate the interpretation of results, many imaging measures are not. Finally, functional brain imaging techniques provide parametric continuous variables with a high resolution of values, whereas behavioural tests provide only non-parametric ranking variables that might be incapable of discriminating slight effects of the intervention. However, the computerised psychophysical tests of attention, memory, etc. provide continuous variables of cognitive performance (reaction time, response time and accuracy). It should also be stressed that these studies tend to show a large interindividual and inter-group variance and that the brain imaging markers are acceptable for use at a group level but not yet at an individual level. This conclusion suggests the need for further investment to develop more precise and effective guidelines for the standardisation, harmonisation and qualification of data collection and its analysis in nutritional intervention studies. This may shorten the time for obtaining final conclusions about the effects of the intervention.

\section{Hypothesis tested regarding the mechanism of action of the intervention}

Because of the limited number of existing reports, we describe the types of studies that could usefully employ the imaging methods described above to examine the effects of a nutritional intervention on the brain. The choice for most appropriate measures depends on the hypothesis regarding the mode of action of a nutritional intervention on brain function (i.e. on which neurostructural, neurophysiological and neurochemical changes are expected due to the intervention). Combination of various imaging measures of different phenomena of the hypothesised working mechanism can provide complementary information and strengthen hypothesis testing. For example, de Wilde et $a l{ }^{(253)}$ reviewed the potential of imaging modalities to test the hypothesis that a nutritional intervention increased the formation of new neuronal membranes and therewith synapse formation and function in $\mathrm{AD}$. To test this specific hypothesis, MRS can be employed to study membrane-related compounds, cerebral metabolic rate of glucose by FDG-PET can provide insights into synaptic functioning and density, and structural MRI can be used to study long-term effects on atrophy rate, while EEG and MEG might be useful to study functional connectivity.
Level (structural, metabolic or functional) and anticipated timescale of the intervention's effects

In this regard, the intrinsic temporal and spatial resolution of the different brain imaging techniques will determine the choice of technique. For example, structural MRI would not be appropriate in an acute intervention context (i.e. single-dose administration or few days of administration). However, these techniques could be included in the general assessment of the experimental subjects if the experimental purposes imply the exclusion of elderly people with preclinical neuropathological processes as indexed by abnormal cortical grey matter, white substance, hippocampus volume, vascular load and so forth. Furthermore, validation of a nutritional intervention in terms of structural MRI effects may yield especially strong evidence in favour of a nutrient, as structural effects may be expected to have long-term consequences on CNS function.

\section{Target population and ethical restrictions}

Most of these imaging techniques are non-invasive and are ethically suitable for use in almost any population throughout the lifespan. However, some can be limited in their use, and this should be addressed during study design to seek alternative imaging markers. For example, PET techniques can be extremely useful in examining the effects of nutritional interventions on brain metabolism and $\mathrm{CBF}$ in human subjects. However, there are ethical restrictions for their use in healthy subjects and these techniques are not suitable for infants and children.

\section{Availability and costs of the techniques}

Some promising procedures might not be viable due to the lack of current availability (i.e. MEG, NIRS or PET) or relatively high costs of their use (i.e. PET and MRI). These aspects may be relevant in the case in which the study plan implies the recruitment of a large number of control and experimental subjects.

\section{Conclusion}

In the present review, we have provided a comprehensive overview of brain imaging markers that have potential utility in nutritional intervention studies examining CNS and cognitive function in healthy human subjects. We have described multimodal MRI, as well as EEG/MEG, NIRS, PET and SPECT techniques, with a focus on the biological relevance of their outcome measures, the practical use and feasibility of the techniques, and the recommended use in terms of acute $v$. chronic nutritional intervention studies. In general, brain imaging markers for nutritional intervention studies can be considered as specific for one or several brain processes and as surrogate instrumental endpoints. They are also suitable to build up translational models to be used in both animals and human subjects to validate preclinical research. However, these markers cannot be considered as a substitute of clinical endpoints in terms of cognitive or behavioural response to a task or challenge. Furthermore, some brain imaging markers can be linked to a broader functional outcome, such as cognition, 
behaviour or wake-sleep cycle, but they certainly do not replace the overall capacity of the brain to behaviourally respond to a specific situation and stimuli that should remain the essential endpoints. The best way to evaluate the effects of food and nutrients on the CNS is to use a proper panel of structural and functional brain imaging markers and of behavioural, psychophysical and clinical (if any) endpoints, in line with the specific working hypotheses on the neural mechanism of action of the intervention. In this framework, the correlation between brain imaging markers and behavioural/psychophysical measurements represents an important aspect of the data analysis design to probe the sensitivity of these neuroimaging markers to the effects of the intervention at an individual level. An ideal view is that international consensus guidelines will be developed in the near future for the use of the appropriate brain imaging techniques for nutritional intervention studies in healthy human subjects. This would be a very promising platform for increasing the use of these markers in future nutritional intervention studies.

\section{Acknowledgements}

The present study was conducted by an expert group of the European Branch of the ILSI (ILSI Europe). The expert group received funding from the ILSI Europe Nutrition and Mental Performance Task Force. Industry members of this task force are listed on the ILSI Europe website at http:// www.ilsi.eu. For further information about ILSI Europe, email info@ilsieurope.be or call +32 277100 14. The opinions expressed herein and the conclusions of this publication are those of the authors and do not necessarily represent the views of ILSI Europe or those of its member companies. Declaration of interest statement: E. A. d. B. is an employee of Unilever; M. H. M. and R. J. W. are employees of DSM; J. M. is an employee of Pfizer Consumer Healthcare; J. W. S. is an employee of Danone Research, Centre for Specialised Nutrition. C. B., E. B. I., D. O. K., P. P., S. V. S. and $\mathrm{K}$. B. W. received an honorarium from ILSI Europe for their participation in this publication and/or reimbursement of their travel and accommodation costs for attending the related meetings. M. E. L. is employed by ILSI Europe. L. S. J. was formerly employed by ILSI Europe. All authors contributed to the discussions, gave inputs for writing the paper and reviewed and approved the content of the final manuscript.

This paper was published as a supplement to British Journal of Nutrition, publication of which was supported by ILSI Europe. The paper has undergone the standard journal formal review process and may be cited.

\section{References}

1. Gomez-Pinilla F (2008) Brain foods: the effects of nutrients on brain function. Nat Rev Neurosci 9, 568-578.

2. Smith KA, Fairburn CG \& Cowen PJ (1997) Relapse of depression after rapid depletion of tryptophan. Lancet 349, 915-919.

3. Isaacs EB, Morley R \& Lucas A (2009) Early diet and general cognitive outcome at adolescence in children born at or below 30 weeks gestation. J Pediatr 155, 229-234.
4. Wittchen HU, Jacobi F, Rehm J, et al. (2011) The size and burden of mental disorders and other disorders of the brain in Europe 2010. Eur Neuropsychopharmacol 21, 655-679.

5. Olesen J, Gustavsson A, Svensson M, et al. (2012) The economic cost of brain disorders in Europe. Eur J Neurol 19, 155-162.

6. Fotuhi M, Mohassel P \& Yaffe K (2009) Fish consumption, long-chain omega- 3 fatty acids and risk of cognitive decline or Alzheimer disease: a complex association. Nat Clin Pract Neurol 5, 140-152.

7. Lucas A, Morley R, Cole TJ, et al. (1990) Early diet in preterm babies and developmental status at 18 months. Lancet 335, 1477-1481.

8. Willatts P, Forsyth JS, DiModugno MK, et al. (1998) Effect of long-chain polyunsaturated fatty acids in infant formula on problem solving at 10 months of age. Lancet 352, 688-691.

9. Scarmeas N, Stern Y, Tang MX, et al. (2006) Mediterranean diet and risk for Alzheimer's disease. Ann Neurol 59, 912-921.

10. Gesch CB, Hammond SM, Hampson SE, et al. (2002) Influence of supplementary vitamins, minerals and essential fatty acids on the antisocial behaviour of young adult prisoners. Randomised, placebo-controlled trial. Br J Psychiatry 181, 22-28.

11. Schmitt JA (2010) Nutrition and cognition: meeting the challenge to obtain credible and evidence-based facts. Nutr Rev 68, Suppl. 1, S2-S5.

12. de Jager CA \& Kovatcheva A (2010) Summary and discussion: methodologies to assess long-term effects of nutrition on brain function. Nutr Rev $\mathbf{6 8}$, Suppl. 1, S53-S58.

13. Fischl B, Salat DH, Busa E, et al. (2002) Whole brain segmentation: automated labeling of neuroanatomical structures in the human brain. Neuron 33, 341-355.

14. Dale AM, Fischl B \& Sereno MI (1999) Cortical surfacebased analysis. I. Segmentation and surface reconstruction. Neuroimage 9, 179-194.

15. Fischl B, Liu A \& Dale AM (2001) Automated manifold surgery: constructing geometrically accurate and topologically correct models of the human cerebral cortex. IEEE Trans Med Imaging 20, 70-80.

16. Fischl B, Sereno MI, Tootell RB, et al. (1999) High-resolution intersubject averaging and a coordinate system for the cortical surface. Hum Brain Mapp 8, 272-284.

17. Fischl B \& Dale AM (2000) Measuring the thickness of the human cerebral cortex from magnetic resonance images. Proc Natl Acad Sci U S A 97, 11050-11055.

18. Segonne F, Grimson E \& Fischl B (2005) A genetic algorithm for the topology correction of cortical surfaces. Inf Process Med Imaging 19, 393-405.

19. Segonne F, Dale AM, Busa E, et al. (2004) A hybrid approach to the skull stripping problem in MRI. Neuroimage 22, 1060-1075.

20. Dale AM \& Sereno MI (1993) Improved localization of cortical activity by combining EEG and MEG with MRI cortical surface reconstruction: a linear approach. J Cogn Neurosci 5, $162-176$.

21. Rosas HD, Liu AK, Hersch S, et al. (2002) Regional and progressive thinning of the cortical ribbon in Huntington's disease. Neurology 58, 695-701.

22. Kuperberg GR, Broome MR, McGuire PK, et al. (2003) Regionally localized thinning of the cerebral cortex in schizophrenia. Arch Gen Psychiatry 60, 878-888.

23. Desikan RS, Segonne F, Fischl B, et al. (2006) An automated labeling system for subdividing the human cerebral cortex on MRI scans into gyral based regions of interest. Neuroimage 31, 968-980.

24. Ashburner J \& Friston KJ (2000) Voxel-based morphometry - the methods. Neuroimage 11, 805-821. 
25. Dubois J, Benders M, Cachia A, et al. (2008) Mapping the early cortical folding process in the preterm newborn brain. Cereb Cortex 18, 1444-1454.

26. Le BD (2003) Looking into the functional architecture of the brain with diffusion MRI. Nat Rev Neurosci 4, 469-480.

27. Mori S \& Zhang J (2006) Principles of diffusion tensor imaging and its applications to basic neuroscience research. Neuron 51, 527-539.

28. Wozniak JR \& Lim KO (2006) Advances in white matter imaging: a review of in vivo magnetic resonance methodologies and their applicability to the study of development and aging. Neurosci Biobehav Rev 30, 762-774.

29. Douaud G, Jbabdi S, Behrens TE, et al. (2011) DTI measures in crossing-fibre areas: increased diffusion anisotropy reveals early white matter alteration in MCI and mild Alzheimer's disease. Neuroimage 55, 880-890.

30. Concha L, Livy DJ, Beaulieu C, et al. (2010) In vivo diffusion tensor imaging and histopathology of the fimbria-fornix in temporal lobe epilepsy. J Neurosci 30, 996-1002.

31. Smith SM, Jenkinson M, Johansen-Berg H, et al. (2006) Tract-based spatial statistics: voxelwise analysis of multisubject diffusion data. Neuroimage 31, 1487-1505.

32. Smith SM, Jenkinson M, Woolrich MW, et al. (2004) Advances in functional and structural MR image analysis and implementation as FSL. Neuroimage 23, Suppl. 1, S208-S219.

33. Huppi PS, Posse S, Lazeyras F, et al. (1991) Magnetic resonance in preterm and term newborns: $1 \mathrm{H}$-spectroscopy in developing human brain. Pediatr Res 30, 574-578.

34. Huppi PS, Fusch C, Boesch C, et al. (1995) Regional metabolic assessment of human brain during development by proton magnetic resonance spectroscopy in vivo and by high-performance liquid chromatography/gas chromatography in autopsy tissue. Pediatr Res 37, 145-150.

35. Ross B \& Bluml S (2001) Magnetic resonance spectroscopy of the human brain. Anat Rec 265, 54-84.

36. Kreis R, Hofmann L, Kuhlmann B, et al. (2002) Brain metabolite composition during early human brain development as measured by quantitative in vivo $1 \mathrm{H}$ magnetic resonance spectroscopy. Magn Reson Med 48, 949-958.

37. Angelie E, Bonmartin A, Boudraa A, et al. (2001) Regional differences and metabolic changes in normal aging of the human brain: proton MR spectroscopic imaging study. AJNR Am J Neuroradiol 22, 119-127.

38. Brooks JC, Roberts N, Kemp GJ, et al. (2001) A proton magnetic resonance spectroscopy study of age-related changes in frontal lobe metabolite concentrations. Cereb Cortex 11, 598-605.

39. Boumezbeur F, Mason GF, de Graaf RA, et al. (2010) Altered brain mitochondrial metabolism in healthy aging as assessed by in vivo magnetic resonance spectroscopy. J Cereb Blood Flow Metab 30, 211-221.

40. Forester BP, Berlow YA, Harper DG, et al. (2010) Agerelated changes in brain energetics and phospholipid metabolism. NMR Biomed 23, 242-250.

41. Chang L, Jiang CS \& Ernst T (2009) Effects of age and sex on brain glutamate and other metabolites. Magn Reson Imaging 27, 142-145.

42. Kaiser LG (2005) Age-related glutamate and glutamine concentration changes in normal human brain: $1 \mathrm{H}$ MR spectroscopy study at 4 T. Neurobiol Aging 26, 665-672.

43. Bozgeyik Z, Burakgazi G, Sen Y, et al. (2008) Age-related metabolic changes in the corpus callosum: assessment with MR spectroscopy. Diagn Interv Radiol 14, 173-176.

44. Charlton RA, McIntyre DJ, Howe FA, et al. (2007) The relationship between white matter brain metabolites and cognition in normal aging: the GENIE study. Brain Res 1164, 108-116.

45. Driscoll I, Hamilton DA, Petropoulos H, et al. (2003) The aging hippocampus: cognitive, biochemical and structural findings. Cereb Cortex 13, 1344-1351.

46. Harada M, Miyoshi H, Otsuka H, et al. (2001) Multivariate analysis of regional metabolic differences in normal ageing on localised quantitative proton MR spectroscopy. Neuroradiology 43, 448-452.

47. van der Knaap MS, van der Grond J, van Rijen PC, et al. (1990) Age-dependent changes in localized proton and phosphorus MR spectroscopy of the brain. Radiology 176, 509-515.

48. Hanaoka S, Takashima S \& Morooka K (1998) Study of the maturation of the child's brain using ${ }^{31} \mathrm{P}$-MRS. Pediatr Neurol 18, 305-310.

49. Pettegrew JW, Withers G, Panchalingam K, et al. (1987) ${ }^{31} \mathrm{P}$ nuclear magnetic resonance (NMR) spectroscopy of brain in aging and Alzheimer's disease. J Neural Transm Suppl 24, 261-268.

50. Robertson NJ, Kuint J, Counsell TJ, et al. (2000) Characterization of cerebral white matter damage in preterm infants using ${ }^{1} \mathrm{H}$ and ${ }^{31} \mathrm{P}$ magnetic resonance spectroscopy. J Cereb Blood Flow Metab 20, 1446-1456.

51. Pettegrew JW, Keshavan MS \& Minshew NJ (1993) ${ }^{31} \mathrm{P}$ nuclear magnetic resonance spectroscopy: neurodevelopment and schizophrenia. Schizophr Bull 19, 35-53.

52. Laureys S, Boly M \& Tononi G (2009) Functional neuroimaging. In The Neurology of Consciousness: Cognitive Neuroscience and Neuropathology, pp. 31-42 [S Laureys and G Tononi, editors]. Academic Press-Elsevier.

53. Raichle ME \& Mintun MA (2006) Brain work and brain imaging. Annu Rev Neurosci 29, 449-476.

54. Roy CS \& Sherrington CS (1890) On the regulation of the blood-supply of the brain. J Physiol 11, 85-158.

55. Ogawa S, Lee TM, Nayak AS, et al. (1990) Oxygenationsensitive contrast in magnetic resonance image of rodent brain at high magnetic fields. Magn Reson Med 14, 68-78.

56. Wharton BA, Morley R, Isaacs EB, et al. (2004) Low plasma taurine and later neurodevelopment. Arch Dis Child Fetal Neonatal Ed 89, F497-F498.

57. Raz N, Lindenberger U, Rodrigue KM, et al. (2005) Regional brain changes in aging healthy adults: general trends, individual differences and modifiers. Cereb Cortex 15, 1676-1689.

58. Raz N, Rodrigue KM \& Haacke EM (2007) Brain aging and its modifiers: insights from in vivo neuromorphometry and susceptibility weighted imaging. Ann N Y Acad Sci 1097, 84-93.

59. Tolsa CB, Zimine S, Warfield SK, et al. (2004) Early alteration of structural and functional brain development in premature infants born with intrauterine growth restriction. Pediatr Res 56, 132-138.

60. Lodygensky GA, Seghier ML, Warfield SK, et al. (2008) Intrauterine growth restriction affects the preterm infant's hippocampus. Pediatr Res 63, 438-443.

61. Dubois J, Benders M, Borradori-Tolsa C, et al. (2008) Primary cortical folding in the human newborn: an early marker of later functional development. Brain 131, 2028-2041.

62. Huppi PS, Murphy B, Maier SE, et al. (2001) Microstructural brain development after perinatal cerebral white matter injury assessed by diffusion tensor magnetic resonance imaging. Pediatrics 107, 455-460.

63. Huppi PS (2004) Microstructural changes in brain development in premature infants with intrauterine growth 
restriction (IUGR): a voxel-based analysis of diffusion tensor imaging (DTI). Pediatr Res 55, 582A.

64. Sizonenko SV, Borradori-Tolsa C, Bauthay DM, et al. (2006) Impact of intrauterine growth restriction and glucocorticoids on brain development: insights using advanced magnetic resonance imaging. Mol Cell Endocrinol 254-255, $163-171$.

65. Borradori C (2003) Brain development in newborns following intrauterine growth restriction (IUGR): a study using 3D-MRI, 1H-MRS and neurodevelopment assessment. Pediatr Res 53, 543A.

66. Taki Y, Hashizume H, Sassa Y, et al. (2010) Breakfast staple types affect brain gray matter volume and cognitive function in healthy children. PLoS One 5, e15213.

67. Lucas A, Gore SM, Cole TJ, et al. (1984) Multicentre trial on feeding low birthweight infants: effects of diet on early growth. Arch Dis Child 59, 722-730.

68. Isaacs EB, Gadian DG, Sabatini S, et al. (2008) The effect of early human diet on caudate volumes and IQ. Pediatr Res 63, 308-314.

69. Isaacs EB, Fischl BR, Quinn BT, et al. (2010) Impact of breast milk on intelligence quotient, brain size, and white matter development. Pediatr Res 67, 357-362.

70. Shaw P, Greenstein D, Lerch J, et al. (2006) Intellectual ability and cortical development in children and adolescents. Nature 440, 676-679.

71. Steinbrink C, Vogt K, Kastrup A, et al. (2008) The contribution of white and gray matter differences to developmental dyslexia: insights from DTI and VBM at 3.0 T. Neuropsychologia 46, 3170-3178.

72. Rykhlevskaia E, Uddin LQ, Kondos L, et al. (2009) Neuroanatomical correlates of developmental dyscalculia: combined evidence from morphometry and tractography. Front Hum Neurosci 3, 51.

73. Blakemore SJ \& Choudhury S (2006) Development of the adolescent brain: implications for executive function and social cognition. J Child Psychol Psychiatry 47, 296-312.

74. Gu Y, Luchsinger JA, Stern Y, et al. (2010) Mediterranean diet, inflammatory and metabolic biomarkers, and risk of Alzheimer's disease. J Alzheimers Dis 22, 483-492.

75. Scarmeas N, Luchsinger JA, Stern Y, et al. (2011) Mediterranean diet and magnetic resonance imaging-assessed cerebrovascular disease. Ann Neurol 69, 257-268.

76. Bowman GL, Silbert LC, Howieson D, et al. (2012) Nutrient biomarker patterns, cognitive function, and MRI measures of brain aging. Neurology 78, 241-249.

77. Feng L, Ng TP, Chuah L, et al. (2006) Homocysteine, folate, and vitamin B-12 and cognitive performance in older Chinese adults: findings from the Singapore Longitudinal Ageing Study. Am J Clin Nutr 84, 1506-1512.

78. Nurk E, Refsum H, Tell GS, et al. (2005) Plasma total homocysteine and memory in the elderly: the Hordaland Homocysteine Study. Ann Neurol 58, 847-857.

79. Seshadri S, Wolf PA, Beiser AS, et al. (2008) Association of plasma total homocysteine levels with subclinical brain injury: cerebral volumes, white matter hyperintensity, and silent brain infarcts at volumetric magnetic resonance imaging in the Framingham Offspring Study. Arch Neurol 65, 642-649.

80. Elias MF, Sullivan LM, D'Agostino RB, et al. (2005) Homocysteine and cognitive performance in the Framingham offspring study: age is important. Am J Epidemiol 162, 644-653.

81. Chee MW, Chen KH, Zheng H, et al. (2009) Cognitive function and brain structure correlations in healthy elderly East Asians. Neuroimage 46, 257-269.
82. den Heijer T, Vermeer SE, Clarke R, et al. (2003) Homocysteine and brain atrophy on MRI of non-demented elderly. Brain 126, 170-175.

83. Sachdev P, Parslow R, Salonikas C, et al. (2004) Homocysteine and the brain in midadult life: evidence for an increased risk of leukoaraiosis in men. Arch Neurol 61, $1369-1376$.

84. Smith AD, Smith SM, de Jager CA, et al. (2010) Homocysteine-lowering by $\mathrm{B}$ vitamins slows the rate of accelerated brain atrophy in mild cognitive impairment: a randomized controlled trial. PLoS One 5, e12244.

85. Virtanen JK, Siscovick DS, Longstreth WT, et al. (2008) Fish consumption and risk of subclinical brain abnormalities on MRI in older adults. Neurology 71, 439-446.

86. Quinn JF, Raman R, Thomas RG, et al. (2010) Docosahexaenoic acid supplementation and cognitive decline in Alzheimer disease: a randomized trial. JAMA 304, 1903-1911.

87. Cohen BM, Renshaw PF, Stoll AL, et al. (1995) Decreased brain choline uptake in older adults. An in vivo proton magnetic resonance spectroscopy study. JAMA $\mathbf{2 7 4}$, 902-907.

88. Agarwal N, Sung YH, Jensen JE, et al. (2010) Short-term administration of uridine increases brain membrane phospholipid precursors in healthy adults: a 31-phosphorus magnetic resonance spectroscopy study at $4 \mathrm{~T}$. Bipolar Disord 12, 825-833.

89. Puri BK (2006) Proton and 31-phosphorus neurospectroscopy in the study of membrane phospholipids and fatty acid intervention in schizophrenia, depression, chronic fatigue syndrome (myalgic encephalomyelitis) and dyslexia. Int Rev Psychiatry 18, 145-147.

90. Puri BK, Koepp MJ, Holmes J, et al. (2007) A 31-phosphorus neurospectroscopy study of omega- 3 long-chain polyunsaturated fatty acid intervention with eicosapentaenoic acid and docosahexaenoic acid in patients with chronic refractory epilepsy. Prostaglandins Leukot Essent Fatty Acids 77, 105-107.

91. Silveri MM, Dikan J, Ross AJ, et al. (2008) Citicoline enhances frontal lobe bioenergetics as measured by phosphorus magnetic resonance spectroscopy. NMR Biomed 21, 1066-1075.

92. Berger GE, Wood SJ, Wellard RM, et al. (2008) Ethyleicosapentaenoic acid in first-episode psychosis. A 1H-MRS study. Neuropsychopharmacology 33, 2467-2473.

93. van der Laan LN, de Ridder DT, Viergever MA, et al. (2011) The first taste is always with the eyes: a meta-analysis on the neural correlates of processing visual food cues. Neuroimage 55, 296-303.

94. Akitsuki Y, Nakawaga S, Sugiura M, et al. (2011) Nutritional quality of breakfast affects cognitive function: an fMRI study. Neurosci Med 2, 192-197.

95. Burton A (2011) Big science for a big problem: ADNI enters its second phase. Lancet Neurol 10, 206-207.

96. Van Petten C (2004) Relationship between hippocampal volume and memory ability in healthy individuals across the lifespan: review and meta-analysis. Neuropsychologia 42, 1394-1413.

97. Tamnes CK, Ostby Y, Walhovd KB, et al. (2010) Neuroanatomical correlates of executive functions in children and adolescents: a magnetic resonance imaging (MRI) study of cortical thickness. Neuropsychologia 48, 2496-2508.

98. Tamnes CK, Ostby Y, Fjell AM, et al. (2010) Brain maturation in adolescence and young adulthood: regional agerelated changes in cortical thickness and white matter volume and microstructure. Cereb Cortex 20, 534-548. 
99. Fjell AM, Westlye LT, Amlien I, et al. (2009) High consistency of regional cortical thinning in aging across multiple samples. Cereb Cortex 19, 2001-2012.

100. Walhovd KB, Fjell AM, Reinvang I, et al. (2005) Cortical volume and speed-of-processing are complementary in prediction of performance intelligence. Neuropsychologia 43, 704-713.

101. Walhovd KB, Westlye LT, Amlien I, et al. (2011) Consistent neuroanatomical age-related volume differences across multiple samples. Neurobiol Aging 32, 916-932.

102. Gusnard DA, Raichle ME \& Raichle ME (2001) Searching for a baseline: functional imaging and the resting human brain. Nat Rev Neurosci 2, 685-694.

103. Magistretti PJ \& Pellerin L (1999) Cellular mechanisms of brain energy metabolism and their relevance to functional brain imaging. Philos Trans $R$ Soc Lond B Biol Sci 354, $1155-1163$.

104. Cabeza R, Grady CL, Nyberg L, et al. (1997) Age-related differences in neural activity during memory encoding and retrieval: a positron emission tomography study. J Neurosci 17, 391-400.

105. Grady CL, McIntosh AR, Horwitz B, et al. (1995) Age-related reductions in human recognition memory due to impaired encoding. Science 269, 218-221.

106. Cabeza R, Anderson ND, Locantore JK, et al. (2002) Aging gracefully: compensatory brain activity in high-performing older adults. Neuroimage 17, 1394-1402.

107. Nyberg L, Salami A, Andersson M, et al. (2010) Longitudinal evidence for diminished frontal cortex function in aging. Proc Natl Acad Sci U S A 107, 22682-22686.

108. Buckner RL, Head D, Parker J, et al. (2004) A unified approach for morphometric and functional data analysis in young, old, and demented adults using automated atlas-based head size normalization: reliability and validation against manual measurement of total intracranial volume. Neuroimage 23, 724-738.

109. Sgouros S, Goldin JH, Hockley AD, et al. (1999) Intracranial volume change in childhood. J Neurosurg 91, 610-616.

110. Fischl B, van der Kouwe AJ, Destrieux C, et al. (2004) Automatically parcellating the human cerebral cortex. Cereb Cortex 14, 11-22.

111. Nielson KA, Langenecker SA, Ross TJ, et al. (2004) Comparability of functional MRI response in young and old during inhibition. Neuroreport 15, 129-133.

112. Huettel SA, Singerman JD \& McCarthy G (2001) The effects of aging upon the hemodynamic response measured by functional MRI. Neuroimage 13, 161-175.

113. Ross MH, Yurgelun-Todd DA, Renshaw PF, et al. (1997) Age-related reduction in functional MRI response to photic stimulation. Neurology 48, 173-176.

114. Ances BM, Liang CL, Leontiev O, et al. (2009) Effects of aging on cerebral blood flow, oxygen metabolism, and blood oxygenation level dependent responses to visual stimulation. Hum Brain Mapp 30, 1120-1132.

115. Samanez-Larkin GR \& D'Esposito M (2008) Group comparisons: imaging the aging brain. Soc Cogn Affect Neurosci 3 , $290-297$.

116. Handwerker DA, Gazzaley A, Inglis BA, et al. (2007) Reducing vascular variability of fMRI data across aging populations using a breathholding task. Hum Brain Mapp 28, 846-859.

117. Handwerker DA, Ollinger JM \& D'Esposito M (2004) Variation of BOLD hemodynamic responses across subjects and brain regions and their effects on statistical analyses. Neuroimage 21, 1639-1651.
118. Walhovd KB, Fjell AM, Dale AM, et al. (2010) Multi-modal imaging predicts memory performance in normal aging and cognitive decline. Neurobiol Aging 31, 1107-1121.

119. Erickson KI, Suever BL, Prakash RS, et al. (2008) Greater intake of vitamins $B_{6}$ and $B_{12}$ spares gray matter in healthy elderly: a voxel-based morphometry study. Brain Res 1199, $20-26$.

120. Berger H (1929) Über das Elektroenkephalogramm des Menschen. Archiv für Psychiatrie und Nervenkrankheiten 87, 527-570.

121. Srinivasan R, Winter WR \& Nunez PL (2006) Source analysis of EEG oscillations using high-resolution EEG and MEG. Prog Brain Res 159, 29-42.

122. Nunez PL, Wingeier BM \& Silberstein RB (2001) Spatialtemporal structures of human alpha rhythms: theory, microcurrent sources, multiscale measurements, and global binding of local networks. Hum Brain Mapp 13, 125-164.

123. Babiloni C, Albertini G, Onorati P, et al. (2009) Interhemispheric functional coupling of eyes-closed resting EEG rhythms in adolescents with Down syndrome. Clin Neurophysiol 120, 1619-1627.

124. Babiloni C, Del Percio C, Valenzano A, et al. (2009) Frontal attentional responses to food size are abnormal in obese subjects: an electroencephalographic study. Clin Neurophysiol 120, 1441-1448.

125. Babiloni C, Del Percio C, Triggiani AI, et al. (2011) Attention cortical responses to enlarged faces are reduced in underweight subjects: an electroencephalographic study. Clin Neurophysiol 122, 1348-1359.

126. Babiloni C, Sara M, Vecchio F, et al. (2009) Cortical sources of resting-state alpha rhythms are abnormal in persistent vegetative state patients. Clin Neurophysiol 120, 719-729.

127. Babiloni C, Pistoia F, Sara M, et al. (2010) Resting state eyesclosed cortical rhythms in patients with locked-in-syndrome: an EEG study. Clin Neurophysiol 121, 1816-1824.

128. Babiloni C, Ferri R, Moretti DV, et al. (2004) Abnormal fronto-parietal coupling of brain rhythms in mild Alzheimer's disease: a multicentric EEG study. Eur J Neurosci 19, 2583-2590.

129. Babiloni C, Ferri R, Binetti G, et al. (2006) Fronto-parietal coupling of brain rhythms in mild cognitive impairment: a multicentric EEG study. Brain Res Bull 69, 63-73.

130. Babiloni C, Frisoni GB, Pievani M, et al. (2008) White matter vascular lesions are related to parietal-to-frontal coupling of EEG rhythms in mild cognitive impairment. Hum Brain Mapp 29, 1355-1367.

131. Babiloni C, Ferri R, Binetti G, et al. (2009) Directionality of EEG synchronization in Alzheimer's disease subjects. Neurobiol Aging 30, 93-102.

132. Babiloni C, Frisoni GB, Vecchio F, et al. (2010) Global functional coupling of resting EEG rhythms is related to white-matter lesions along the cholinergic tracts in subjects with amnesic mild cognitive impairment. J Alzheimers Dis 19, 859-871.

133. Klimesch W (1999) EEG alpha and theta oscillations reflect cognitive and memory performance: a review and analysis. Brain Res Brain Res Rev 29, 169-195.

134. Rossini PM, Rossi S, Babiloni C, et al. (2007) Clinical neurophysiology of aging brain: from normal aging to neurodegeneration. Prog Neurobiol 83, 375-400.

135. Koles ZJ, Lind JC \& Flor-Henry P (2010) Gender differences in brain functional organization during verbal and spatial cognitive challenges. Brain Topogr 23, 199-204.

136. Spironelli C, Penolazzi B \& Angrilli A (2010) Gender differences in reading in school-aged children: an early ERP study. Dev Neuropsychol 35, 357-375. 
137. Ruxton CHS (2008) The impact of caffeine on mood, cognitive function, performance and hydration: a review of benefits and risks. Nutr Bull 33, 15-25.

138. Dimpfel W, Schober F \& Spuler M (1993) The influence of caffeine on human EEG under resting conditions and during mental loads. Clin Investig 71, 197-207.

139. Gevins A, Smith ME \& McEvoy LK (2002) Tracking the cognitive pharmacodynamics of psychoactive substances with combinations of behavioral and neurophysiological measures. Neuropsychopharmacology 26, 27-39.

140. Keane MA, James JE \& Hogan MJ (2007) Effects of dietary caffeine on topographic EEG after controlling for withdrawal and withdrawal reversal. Neuropsychobiology 56, 197-207.

141. Keane MA \& James JE (2008) Effects of dietary caffeine on EEG, performance and mood when rested and sleep restricted. Hum Psychopharmacol 23, 669-680.

142. Kenemans JL \& Lorist MM (1995) Caffeine and selective visual processing. Pharmacol Biochem Behav 52, 461-471.

143. Tieges Z, Richard RK, Snel J, et al. (2004) Caffeine strengthens action monitoring: evidence from the error-related negativity. Brain Res Cogn Brain Res 21, 87-93.

144. Tieges Z, Snel J, Kok A, et al. (2007) Effects of caffeine on anticipatory control processes: evidence from a cued taskswitch paradigm. Psychophysiology 44, 561-578.

145. Lorist MM \& Tops M (2003) Caffeine, fatigue, and cognition. Brain $\operatorname{Cog} n$ 53, 82-94.

146. Pfurtscheller G (1992) Event-related synchronization (ERS): an electrophysiological correlate of cortical areas at rest. Electroencephalogr Clin Neurophysiol 83, 62-69.

147. Galati S, Stanzione P, D'Angelo V, et al. (2009) The pharmacological blockade of medial forebrain bundle induces an acute pathological synchronization of the corticosubthalamic nucleus-globus pallidus pathway. I Physiol $\mathbf{5 8 7}, 4405-4423$.

148. Knott VJ \& Harr A (1997) Aging, smoking and EEG coherence: a preliminary study. Clin Electroencephalogr 28, 236-244

149. Molnar M, Boha R, Czigler B, et al. (2009) The acute effect of low-dose alcohol on working memory during mental arithmetic: II. Changes of nonlinear and linear EEG-complexity in the theta band, heart rate and electrodermal activity. Int J Psychophysiol 73, 138-142.

150. Reid MS, Flammino F, Howard B, et al. (2006) Topographic imaging of quantitative EEG in response to smoked cocaine self-administration in humans. Neuropsychopharmacology 31, 872-884.

151. Struve FA, Manno BR, Kemp P, et al. (2003) Acute marihuana (THC) exposure produces a "transient" topographic quantitative EEG profile identical to the "persistent" profile seen in chronic heavy users. Clin Electroencephalogr $\mathbf{3 4}$ $75-83$.

152. Scheltens P, Twisk JW, Blesa R, et al. (2012) Efficacy of Souvenaid in mild Alzheimer's disease: results from a randomized, controlled trial. J Alzheimers Dis 31, 225-236.

153. Birch EE, Birch DG, Hoffman DR, et al. (1992) Dietary essential fatty acid supply and visual acuity development. Invest Ophthalmol Vis Sci 33, 3242-3253.

154. Birch EE, Carlson SE, Hoffman DR, et al. (2010) The DIAMOND (DHA Intake And Measurement of Neural Development) Study: a double-masked, randomized controlled clinical trial of the maturation of infant visual acuity as a function of the dietary level of docosahexaenoic acid. Am J Clin Nutr 91, 848-859.

155. Fontani G, Corradeschi F, Felici A, et al. (2005) Cognitive and physiological effects of omega-3 polyunsaturated fatty acid supplementation in healthy subjects. Eur J Clin Invest 35, 691-699.

156. Fontani G, Lodi L, Migliorini S, et al. (2009) Effect of omega-3 and policosanol supplementation on attention and reactivity in athletes. J Am Coll Nutr 28, Suppl., 473S-481S.

157. Helland IB, Saugstad OD, Smith L, et al. (2001) Similar effects on infants of $n-3$ and $n-6$ fatty acids supplementation to pregnant and lactating women. Pediatrics $\mathbf{1 0 8}$ E82.

158. Jing H, Pivik RT, Dykman RA, et al. (2007) Effects of breast milk and milk formula diets on synthesized speech soundinduced event-related potentials in 3- and 6-month-old infants. Dev Neuropsychol 31, 349-362.

159. Jing H, Gilchrist JM, Badger TM, et al. (2010) A longitudinal study of differences in electroencephalographic activity among breastfed, milk formula-fed, and soy formula-fed infants during the first year of life. Early Hum Dev 86, $119-125$.

160. Makrides M, Neumann MA, Jeffrey B, et al. (2000) A randomized trial of different ratios of linoleic to alpha-linolenic acid in the diet of term infants: effects on visual function and growth. Am J Clin Nutr 71, 120-129.

161. Unay B, Sarici SU, Ulas UH, et al. (2004) Nutritional effects on auditory brainstem maturation in healthy term infants. Arch Dis Child Fetal Neonatal Ed 89, F177-F179.

162. van Wezel-Meijler G, van der Knaap MS, Huisman J, et al. (2002) Dietary supplementation of long-chain polyunsaturated fatty acids in preterm infants: effects on cerebral maturation. Acta Paediatr 91, 942-950.

163. Hoffman DR, Birch EE, Castaneda YS, et al. (2003) Visual function in breast-fed term infants weaned to formula with or without long-chain polyunsaturates at 4 to 6 months: a randomized clinical trial. J Pediatr 142, 669-677.

164. Hoffman DR, Theuer RC, Castaneda YS, et al. (2004) Maturation of visual acuity is accelerated in breast-fed term infants fed baby food containing DHA-enriched egg yolk. J Nutr 134, 2307-2313.

165. Birch EE, Castaneda YS, Wheaton DH, et al. (2005) Visual maturation of term infants fed long-chain polyunsaturated fatty acid-supplemented or control formula for $12 \mathrm{mo}$. Am J Clin Nutr 81, 871-879.

166. Birch EE, Garfield S, Hoffman DR, et al. (2000) A randomized controlled trial of early dietary supply of long-chain polyunsaturated fatty acids and mental development in term infants. Dev Med Child Neurol 42, 174-181.

167. Bougle D, Denise P, Vimard F, et al. (1999) Early neurological and neuropsychological development of the preterm infant and polyunsaturated fatty acids supply. Clin Neurophysiol 110, 1363-1370.

168. Parra-Cabrera S, Moreno-Macias H, Mendez-Ramirez I, et al. (2008) Maternal dietary omega fatty acid intake and auditory brainstem-evoked potentials in Mexican infants born at term: cluster analysis. Early Hum Dev 84, 51-57.

169. Henriksen C, Haugholt K, Lindgren M, et al. (2008) Improved cognitive development among preterm infants attributable to early supplementation of human milk with docosahexaenoic acid and arachidonic acid. Pediatrics 121, 1137-1145.

170. Capotosto P, Babiloni C, Romani GL, et al. (2009) Frontoparietal cortex controls spatial attention through modulation of anticipatory alpha rhythms. J Neurosci 29 , 5863-5872.

171. Hou C, Good WV \& Norcia AM (2007) Validation study of VEP vernier acuity in normal-vision and amblyopic adults. Invest Ophthalmol Vis Sci 48, 4070-4078. 
172. Del Parigi A, Chen K, Gautier JF, et al. (2002) Sex differences in the human brain's response to hunger and satiation. Am J Clin Nutr 75, 1017-1022.

173. Girouard H \& Iadecola C (2006) Neurovascular coupling in the normal brain and in hypertension, stroke, and Alzheimer disease. J Appl Physiol 100, 328-335.

174. Steinbrink J, Villringer A, Kempf F, et al. (2006) Illuminating the BOLD signal: combined fMRI-fNIRS studies. Magn Reson Imaging 24, 495-505.

175. Lloyd-Fox S, Blasi A \& Elwell CE (2010) Illuminating the developing brain: the past, present and future of functional near infrared spectroscopy. Neurosci Biobehav Rev 34, 269-284.

176. Leff DR, Orihuela-Espina F, Elwell CE, et al. (2011) Assessment of the cerebral cortex during motor task behaviours in adults: a systematic review of functional near infrared spectroscopy (fNIRS) studies. Neuroimage 54, 2922-2936.

177. Okamoto M \& Dan I (2007) Functional near-infrared spectroscopy for human brain mapping of taste-related cognitive functions. J Biosci Bioeng 103, 207-215.

178. Schecklmann M, Ehlis AC, Plichta MM, et al. (2008) Functional near-infrared spectroscopy: a long-term reliable tool for measuring brain activity during verbal fluency. Neuroimage 43, 147-155.

179. Kameyama M, Fukuda M, Uehara T, et al. (2004) Sex and age dependencies of cerebral blood volume changes during cognitive activation: a multichannel near-infrared spectroscopy study. Neuroimage 22, 1715-1721.

180. Safonova LP, Michalos A, Wolf U, et al. (2004) Agecorrelated changes in cerebral hemodynamics assessed by near-infrared spectroscopy. Arch Gerontol Geriatr 39, 207-225.

181. Herrmann MJ, Walter A, Ehlis AC, et al. (2006) Cerebral oxygenation changes in the prefrontal cortex: effects of age and gender. Neurobiol Aging 27, 888-894.

182. Schroeter ML, Zysset S, Kruggel F, et al. (2003) Age dependency of the hemodynamic response as measured by functional near-infrared spectroscopy. Neuroimage $\mathbf{1 9}$, 555-564.

183. Kim YS, Bogert LW, Immink RV, et al. (2011) Effects of aging on the cerebrovascular orthostatic response. Neurobiol Aging 32, 344-353.

184. Harada H, Nashihara H, Morozumi K, et al. (2007) A comparison of cerebral activity in the prefrontal region between young adults and the elderly while driving. I Physiol Anthropol 26, 409-414.

185. Strangman G, Boas DA \& Sutton JP (2002) Non-invasive neuroimaging using near-infrared light. Biol Psychiatry 52, 679-693.

186. Pellicer A \& Bravo MC (2011) Near-infrared spectroscopy: a methodology-focused review. Semin Fetal Neonatal Med 16, 42-49.

187. Wolf M, Ferrari M \& Quaresima V (2007) Progress of near-infrared spectroscopy and topography for brain and muscle clinical applications. J Biomed Opt 12, 062104.

188. Hoshi Y (2005) Functional near-infrared spectroscopy: potential and limitations in neuroimaging studies. Int Rev Neurobiol 66, 237-266.

189. Cui X, Bray S, Bryant DM, et al. (2011) A quantitative comparison of NIRS and fMRI across multiple cognitive tasks. Neuroimage 54, 2808-2821.

190. Huppert TJ, Hoge RD, Diamond SG, et al. (2006) A temporal comparison of BOLD, ASL, and NIRS hemodynamic responses to motor stimuli in adult humans. Neuroimage 29, 368-382
191. Jobsis FF (1977) Noninvasive, infrared monitoring of cerebral and myocardial oxygen sufficiency and circulatory parameters. Science 198, 1264-1267.

192. Ghanayem NS, Wernovsky G \& Hoffman GM (2011) Nearinfrared spectroscopy as a hemodynamic monitor in critical illness. Pediatr Crit Care Med 12, S27-S32.

193. Kasman N \& Brady K (2011) Cerebral oximetry for pediatric anesthesia: why do intelligent clinicians disagree? Paediatr Anaesth 21, 473-478.

194. Franceschini MA, Thaker S, Themelis G, et al. (2007) Assessment of infant brain development with frequency-domain near-infrared spectroscopy. Pediatr Res 61, 546-551.

195. Wallois F, Patil A, Heberle C, et al. (2010) EEG-NIRS in epilepsy in children and neonates. Neurophysiol Clin 40, 281-292.

196. Cohn SM (2007) Near-infrared spectroscopy: potential clinical benefits in surgery. J Am Coll Surg 205, 322-332.

197. La MM, David A, Gaeta R, et al. (2010) [Near infrared spectroscopy for cerebral monitoring during cardiovascular surgery]. Clin Ter 161, 549-553.

198. Len TK \& Neary JP (2011) Cerebrovascular pathophysiology following mild traumatic brain injury. Clin Physiol Funct Imaging 31, 85-93.

199. Arai H, Takano M, Miyakawa K, et al. (2006) A quantitative near-infrared spectroscopy study: a decrease in cerebral hemoglobin oxygenation in Alzheimer's disease and mild cognitive impairment. Brain $\operatorname{Cogn}$ 61, 189-194.

200. Ohi K, Hashimoto R, Yasuda Y, et al. (2011) The SIGMAR1 gene is associated with a risk of schizophrenia and activation of the prefrontal cortex. Prog Neuropsychopharmacol Biol Psychiatry 35, 1309-1315.

201. Takeshi K, Nemoto T, Fumoto M, et al. (2010) Reduced prefrontal cortex activation during divergent thinking in schizophrenia: a multi-channel NIRS study. Prog Neuropsychopharmacol Biol Psychiatry 34, 1327-1332.

202. Vanderhaegen J, Naulaers G, van Huffel S, et al. (2010) Cerebral and systemic hemodynamic effects of intravenous bolus administration of propofol in neonates. Neonatology 98, 57-63.

203. Weber P, Lutschg J \& Fahnenstich H (2007) Methylphenidate-induced changes in cerebral hemodynamics measured by functional near-infrared spectroscopy. J Child Neurol 22, 812-817.

204. Tsujii T, Masuda S, Yamamoto E, et al. (2009) Effects of sedative and nonsedative antihistamines on prefrontal activity during verbal fluency task in young children: a near-infrared spectroscopy (NIRS) study. Psychopharmacology (Berl) 207, 127-132.

205. Watanabe Y, Tanaka H, Dan I, et al. (2011) Monitoring cortical hemodynamic changes after sumatriptan injection during migraine attack by near-infrared spectroscopy. Neurosci Res 69, 60-66.

206. Brassard P, Seifert T, Wissenberg M, et al. (2010) Phenylephrine decreases frontal lobe oxygenation at rest but not during moderately intense exercise. I Appl Physiol 108, $1472-1478$.

207. Bonoczk P, Panczel G \& Nagy Z (2002) Vinpocetine increases cerebral blood flow and oxygenation in stroke patients: a near infrared spectroscopy and transcranial Doppler study. Eur J Ultrasound 15, 85-91.

208. Tracy MB, Klimek J, Hinder M, et al. (2010) Does caffeine impair cerebral oxygenation and blood flow velocity in preterm infants? Acta Paediatr 99, 1319-1323.

209. Kennedy DO \& Haskell CF (2011) Cerebral blood flow and behavioural effects of caffeine in habitual and non-habitual 
consumers of caffeine: a near infrared spectroscopy study. Biol Psychol 86, 298-306.

210. Kennedy DO, Wightman EL, Reay JL, et al. (2010) Effects of resveratrol on cerebral blood flow variables and cognitive performance in humans: a double-blind, placebo-controlled, crossover investigation. Am J Clin Nutr 91, 1590-1597.

211. Wightman EL, Haskell CF, Forster J, et al. (2012) Epigallocatechin gallate (EGCG), cerebral blood flow parameters, cognitive performance and mood in healthy humans: a double-blind, placebo-controlled, crossover investigation. Hum Psychopharmacol 27, 177-186.

212. Watanabe A, Kato N \& Kato T (2002) Effects of creatine on mental fatigue and cerebral hemoglobin oxygenation. Neurosci Res 42, 279-285.

213. Jackson PA, Reay JL, Scholey AB, et al. (2012) DHA-rich oil modulates the cerebral haemodynamic response to cognitive tasks in healthy young adults: a near IR spectroscopy pilot study. BrJ Nutr 107, 1093-1098.

214. Jackson PA, Reay JL, Scholey AB, et al. (2012) Docosahexaenoic acid-rich fish oil modulates the cerebral hemodynamic response to cognitive tasks in healthy young adults. Biol Psychol 89, 183-190.

215. Horwitz B, Friston KJ \& Taylor JG (2000) Neural modeling and functional brain imaging: an overview. Neural Netw 13, $829-846$.

216. Wong DR \& Brasic JR (2001) In vivo imaging of neurotransmitter systems in neuropsychiatry. Clin Neurosci Res 1, 35-45.

217. Holcomb HH, Links J, Smith C, et al. (1989) Positron mission tomography measuring the metabolic and neurochemical characteristics of the living human nervous system. In Brain Imaging: Applications in Psychiatry, pp. 235-370 [N Andreasen, editor]. Washington, DC: American Psychiatric Press, Inc.

218. Reivich M, Kuhl D, Wolf A, et al. (1979) The [18F]fluorodeoxyglucose method for the measurement of local cerebral glucose utilization in man. Circ Res 44, 127-137.

219. Sokoloff L, Reivich M, Kennedy C, et al. (1977) The [14C]deoxyglucose method for the measurement of local cerebral glucose utilization: theory, procedure, and normal values in the conscious and anesthetized albino rat. J Neurochem 28, 897-916.

220. Sokoloff L (1982) The radioactive deoxyglucose method, theory, procedure and application for the measurement of local cerebral glucose utilization in the central nervous system. In Advances in Neurochemistry, pp. 1-82 [BW Agranoff and MH Aprison, editors]. New York, NY: Plenum Press.

221. Paus $\mathrm{T}$ (2010) A primer for brain imaging: a tool for evidence-based studies of nutrition? Nutr Rev 68, Suppl. 1, S29-S37.

222. Wong TZ, van der Westhuizen GJ \& Coleman RE (2002) Positron emission tomography imaging of brain tumors. Neuroimaging Clin N Am 12, 615-626.

223. Gautier JF, Chen K, Salbe AD, et al. (2000) Differential brain responses to satiation in obese and lean men. Diabetes $\mathbf{4 9}$, 838-846.

224. Tataranni PA, Gautier JF, Chen K, et al. (1999) Neuroanatomical correlates of hunger and satiation in humans using positron emission tomography. Proc Natl Acad Sci US A 96, 4569-4574.

225. Le DS, Chen K, Pannacciulli N, et al. (2009) Reanalysis of the obesity-related attenuation in the left dorsolateral prefrontal cortex response to a satiating meal using gyral regions-of-interest. J Am Coll Nutr 28, 667-673.
226. Small GW, Silverman DH, Siddarth P, et al. (2006) Effects of a 14-day healthy longevity lifestyle program on cognition and brain function. Am J Geriatr Psychiatry 14, 538-545.

227. Del Parigi A, Chen K, Salbe AD, et al. (2007) Successful dieters have increased neural activity in cortical areas involved in the control of behavior. Int J Obes (Lond) 31, 440-448.

228. Stunkard AJ \& Messick S (1985) The three-factor eating questionnaire to measure dietary restraint, disinhibition and hunger. $J$ Psychosom Res 29, 71-83.

229. Miller EK (1999) The prefrontal cortex: complex neural properties for complex behavior. Neuron 22, 15-17.

230. Rolls ET (2000) The orbitofrontal cortex and reward. Cereb Cortex 10, 284-294.

231. Hinton EC, Parkinson JA, Holland AJ, et al. (2004) Neural contributions to the motivational control of appetite in humans. Eur J Neurosci 20, 1411-1418.

232. Nugent S, Croteau E, Pifferi F, et al. (2011) Brain and systemic glucose metabolism in the healthy elderly following fish oil supplementation. Prostaglandins Leukot Essent Fatty Acids 85, 287-291.

233. Grimaldi BL (2002) The central role of magnesium deficiency in Tourette's syndrome: causal relationships between magnesium deficiency, altered biochemical pathways and symptoms relating to Tourette's syndrome and several reported comorbid conditions. Med Hypotheses 58, 47-60.

234. Garcia-Lopez R, Perea-Milla E, Garcia CR, et al. (2009) New therapeutic approach to Tourette Syndrome in children based on a randomized placebo-controlled doubleblind phase IV study of the effectiveness and safety of magnesium and vitamin $\mathrm{B}_{6}$. Trials $\mathbf{1 0}, 16$.

235. Frank Y \& Pavlakis SG (2001) Brain imaging in neurobehavioral disorders. Pediatr Neurol 25, 278-287.

236. Lepping P \& Huber M (2010) Role of zinc in the pathogenesis of attention-deficit hyperactivity disorder: implications for research and treatment. CNS Drugs 24, 721-728.

237. Ferri CP, Prince M, Brayne C, et al. (2005) Global prevalence of dementia: a Delphi consensus study. Lancet 366 , 2112-2117.

238. Cunnane S, Nugent S, Roy M, et al. (2011) Brain fuel metabolism, aging, and Alzheimer's disease. Nutrition 27, 3-20.

239. Pietrini P \& Rapoport SI (2000) Functional brain imaging: cerebral blood flow and glucose metabolism in healthy human aging. In Textbook of Geriatric Neuropsychiatry, pp. 239-265 [CE Coffey and JL Cumming, editors] Washington, DC: American Psychiatric Press.

240. Pietrini P, Alexander GE, Furey ML, et al. (2000) The neurometabolic landscape of cognitive decline: in vivo studies with positron emission tomography in Alzheimer's disease. Int J Psychophysiol 37, 87-98.

241. Eckelman WC, Grissom M, Conklin J, et al. (1984) In vivo competition studies with analogues of 3-quinuclidinyl benzilate. J Pharm Sci 73, 529-534.

242. Kung HF, Ohmomo Y \& Kung MP (1990) Current and future radiopharmaceuticals for brain imaging with single photon emission computed tomography. Semin Nucl Med 20, 290-302.

243. Newberg AB, Alavi A \& Payer F (1995) Single photon emission computed tomography in Alzheimer's disease and related disorders. Neuroimaging Clin N Am 5, 103-123.

244. Devous MD Sr, Stokely EM \& Bonte FJ (1985) Quantitative imaging of regional cerebral blood flow in man by dynamic single-photon tomography. In Radionuclide Imaging of the Brain, pp. 135-162 [BL Holman, editor]. New York, NY: Churchill Livingstone.

245. Juni JE, Waxman AD, Devous MD, et al. (1998) Procedure guideline for brain perfusion SPECT using technetium-99m 
radiopharmaceuticals. Society of Nuclear Medicine. $J \mathrm{NuCl}$ Med 39, 923-926.

246. Masdeu JC, Brass LM, Holman BL, et al. (1994) Brain singlephoton emission computed tomography. Neurology $\mathbf{4 4}$ 1970-1977.

247. Van Heertum RL \& Tikofsky RS (2003) Positron emission tomography and single-photon emission computed tomography brain imaging in the evaluation of dementia. Semin Nucl Med 33, 77-85.

248. Usai P, Serra A, Marini B, et al. (2004) Frontal cortical perfusion abnormalities related to gluten intake and associated autoimmune disease in adult coeliac disease: $99 \mathrm{mTc}-\mathrm{ECD}$ brain SPECT study. Dig Liver Dis 36, 513-518.

249. Karhunen LJ, Vanninen EJ, Kuikka JT, et al. (2000) Regional cerebral blood flow during exposure to food in obese binge eating women. Psychiatry Res 99, 29-42.

250. de Weijer BA, van de Giessen E, van Amelsvoort TA, et al. (2011) Lower striatal dopamine D2/3 receptor availability in obese compared with non-obese subjects. EJNMMI Res 1, 37 .

251. Bender A, Koch W, Elstner M, et al. (2006) Creatine supplementation in Parkinson disease: a placebo-controlled randomized pilot trial. Neurology 67, 1262-1264.

252. Blundo C, Marin D \& Ricci M (2011) Vitamin $B_{12}$ deficiency associated with symptoms of frontotemporal dementia. Neurol Sci 32, 101-105.

253. de Wilde MC, Kamphuis PJ, Sijben JW, et al. (2011) Utility of imaging for nutritional intervention studies in Alzheimer's disease. Eur J Pharmacol 668, Suppl. 1, S59-S69.

254. Robertson NJ \& Cox IJ (2002) Magnetic resonance spectroscopy of the neonatal brain. In MRI of the Neonatal Brain, [MA Rutherford, editor]. London: Saunders Ltd.

255. Buchli R, Martin E, Boesiger P, et al. (1994) Developmental changes of phosphorus metabolite concentrations in the human brain: a ${ }^{31} \mathrm{P}$ magnetic resonance spectroscopy study in vivo. Pediatr Res 35, 431-435. 